\title{
Ferroptosis in Acute Central Nervous System Injuries: The Future Direction?
}

\author{
Lesang Shen ${ }^{1 \dagger}$, Danfeng Lin'ti, Xiaoyi $\mathrm{Li}^{3}$, Haijian $\mathrm{Wu}^{4}$, Cameron Lenahan ${ }^{5,6}$, \\ Yuanbo Pan ${ }^{5,6}$, Weilin $\mathrm{Xu}^{5,6}$, Yiding Chen ${ }^{1 *}$, Anwen Shao ${ }^{4 *}$ and Jianmin Zhang ${ }^{4}$ \\ ${ }^{1}$ Department of Breast Surgery, The Second Affiliated Hospital, Zhejiang University School of Medicine, Hangzhou, China, \\ ${ }^{2}$ Department of Surgical Oncology, The Second Affiliated Hospital, Zhejiang University School of Medicine, Hangzhou, \\ China, ${ }^{3}$ Department of Nuclear Medicine and PET-CT Center, The Second Hospital, Zhejiang University School of Medicine, \\ Hangzhou, China, ${ }^{4}$ Department of Neurosurgery, The Second Affiliated Hospital, Zhejiang University School of Medicine, \\ Hangzhou, China, ${ }^{5}$ Burrell College of Osteopathic Medicine, Las Cruces, NM, United States, ${ }^{6}$ Center for Neuroscience \\ Research, School of Medicine, Loma Linda University, Loma Linda, CA, United States
}

\section{OPEN ACCESS}

Edited by:

Alexander A. Mongin, Albany Medical College, United States

Reviewed by:

Sandra Hewett

Syracuse University, United States

Chunying Li,

Georgia State University,

United States

*Correspondence:

Anwen Shao

21118116@zju.edu.cn:

anwenshao@sina.com

Yiding Chen

ydchen@zju.edu.cn

${ }^{\dagger}$ These authors have contributed equally to this work

Specialty section:

This article was submitted to

Cell Death and Survival,

a section of the journal

Frontiers in Cell and Developmental

Biology

Received: 11 March 2020

Accepted: 18 June 2020

Published: 15 July 2020

Citation:

Shen L, Lin D, Li X, Wu H, Lenahan C, Pan Y, Xu W, Chen Y,

Shao $A$ and Zhang J (2020)

Ferroptosis in Acute Central Nervous

System Injuries: The Future Direction?

Front. Cell Dev. Biol. 8:594.

doi: 10.3389/fcell.2020.00594
Acute central nervous system (CNS) injuries, such as stroke, traumatic brain injury (TBI), and spinal cord injury (SCl) present a grave health care challenge worldwide due to high morbidity and mortality, as well as limited clinical therapeutic strategies. Established literature has shown that oxidative stress (OS), inflammation, excitotoxicity, and apoptosis play important roles in the pathophysiological processes of acute CNS injuries. Recently, there have been many studies on the topic of ferroptosis, a form of regulated cell death characterized by the accumulation of iron-dependent lipid peroxidation. Some studies have revealed an emerging connection between acute CNS injuries and ferroptosis. Ferroptosis, induced by the abnormal metabolism of lipids, glutathione (GSH), and iron, can accelerate acute CNS injuries. However, pharmaceutical agents, such as iron chelators, ferrostatin-1 (Fer-1), and liproxstatin-1 (Lip-1), can inhibit ferroptosis and may have neuroprotective effects after acute CNS injuries. However, the specific mechanisms underlying this connection has not yet been clearly elucidated. In this paper, we discuss the general mechanisms of ferroptosis and its role in stroke, TBI, and $\mathrm{SCl}$. We also summarize ferroptosis-related drugs and highlight the potential therapeutic strategies in treating various acute CNS injuries. Additionally, this paper suggests a testable hypothesis that ferroptosis may be a novel direction for further research of acute CNS injuries by providing corresponding evidence.

Keywords: ferroptosis, iron metabolism, lipid metabolism, stroke, traumatic brain injury, spinal cord injury, therapy

\section{INTRODUCTION}

Acute CNS injuries, including stroke, TBI, and SCI, are a major burden of morbidity and mortality worldwide (GBD, 2016, 2019). Each year, approximately 80 million individuals in the United States suffer a stroke. Moreover, deaths caused by stroke contribute to nearly $5 \%$ of all deaths in the United States. Ischemic stroke accounts for $87 \%$ of all strokes, with ICH comprising the remaining $10 \%$ (Benjamin et al., 2019). Another neurological disease worth mentioning is TBI, which has a global incidence of more than 50 million cases annually (Maas et al., 2017; Jiang et al., 2019). Regarding the mechanisms associated with acute CNS injuries, previous literature has shown that 
various mechanisms, including OS, inflammation, excitotoxicity, and apoptosis, play important roles in the pathophysiological processes of acute CNS, and targeting these mechanisms may provide neuroprotection (Roth et al., 2014; Chamorro et al., 2016; Duan et al., 2019; Nazemi et al., 2020). However, there is a lack of effective therapeutic strategies in treating long-term CNS injuries. Patients who survive CNS injuries often have long-term disabilities due to substantial neurological deficits and impaired tissue function, therefore requiring subsequent lifelong care. New therapeutic approaches are urgently required to improve outcomes of patients with acute CNS injuries. In recent years, there has been increasing interest in ferroptosis, suggesting a potential role of ferroptosis in acute CNS injuries and offering opportunities for novel pharmacological interventions, as ferroptosis can be modulated by small molecules (Friedmann Angeli et al., 2014; Lewerenz et al., 2018; Alim et al., 2019).

Ferroptosis, first observed in response to treatment of tumor cells via small-molecule chemical probes, is a newly identified form of regulated cell death characterized by the accumulation of iron-mediated lipid peroxides (Dixon et al., 2012). It differs from other programmed cell deaths (e.g., apoptosis, necrosis, and autophagy) at the morphological, biological, and genetic levels (Dixon et al., 2012). Regarding the function of ferroptosis within the tumor, it is associated with malignant transformation, cancer progression, and drug resistance [for review see Su et al. (2020)]. Moreover, ferroptosis regulation may be useful for anti-cancer therapy (Guo et al., 2019; Su et al., 2020). Although ferroptosis was first defined in cancer cells and has potential in cancer treatment, the latest experimental results have identified its role in the pathophysiology of acute organ injuries, such as acute kidney, lung, and brain injuries (Dixon et al., 2012; Friedmann Angeli et al., 2014; Kenny et al., 2019; Hu et al., 2020; Li Y.C. et al., 2020). More importantly, ferroptosis can cause neuronal cell death and neurological deficits in CNS injuries and human neurodegenerative diseases (Dixon et al., 2012; Morris et al., 2018). Therefore, targeting ferroptosis through effective antiferroptotic agents may provide direction for treating acute CNS injuries (Tuo et al., 2017; Zille et al., 2017; Kenny et al., 2019).

Abbreviations: 4-HNE, 4-hydroxy-2-nonenal; AA, arachidonic acid; ACSL4, acyl-CoA synthetase long-chain family member 4; AdA, adrenic acid; ALOX5, arachidonate 5-lipoxygenase; BBB, blood-brain barrier; BMSC, bone marrow mesenchymal stem cells; BPS, bathophenanthrolinedisulfonic acid; BSO, buthionine sulfoximine; CCI, cortical impact injury; CNS, central nervous system; CoQ10, coenzyme Q10; COX-2, cyclooxygenase-2; DFO, deferoxamine; DFP, deferiprone; DMT1, divalent metal transporter 1; EC, (-)-epicatechin; $\mathrm{Fe}^{2+}$, ferrous iron; $\mathrm{Fe}^{3+}$, ferric iron; Fer-1, ferrostatin-1; FPN, ferroportin; FSP1, ferroptosis suppressor protein 1; FTH1, ferritin heavy chain 1; FTL, ferritin light chain; GPX4, glutathione peroxidases 4; GSH, glutathione; Hb, hemoglobin; HIF- $1 \alpha$, hypoxia-inducible factor $1 \alpha$; HIFPHD, hypoxia-inducible factor prolyl hydroxylase; I/R, ischemia/reperfusion; $\mathrm{ICH}$, intracerebral hemorrhage; IREB2, iron metabolism essential factor iron response element binding protein 2; Lip-1, liproxstatin-1; LOX, lipoxygenases; LPCAT3, lysophosphatidylcholine acyltransferase 3; MCAO, middle cerebral artery occlusion; MDA, malondialdehyde; NAC, N-acetylcysteine; NACA, $\mathrm{N}$-acetylcysteine amide; Nrf2, nuclear factor erythroid 2-related factor; OS, oxidative stress; PEBP1, phosphatidylethanolamine-binding protein 1; PTGS2, prostaglandin-endoperoxide synthase 2; PUFA, polyunsaturated fatty acid; ROS, reactive oxygen species; RSL3, RAS synthetic lethal 3; SBI, secondary brain injury; SCI, spinal cord injury; Se, selenium; STEAP3, six-transmembrane epithelial antigen of the prostate 3; TBI, traumatic brain injury; TEM, transmission electron microscopy; TF, transferrin; TFR, transferrin receptor.
So, what is the underlying mechanism of ferroptosis, and how does it affect acute CNS injuries?

\section{DISCOVERY AND MECHANISMS OF FERROPTOSIS}

Small-molecule probes are valuable tools for studying different types of regulated cell death (Gangadhar and Stockwell, 2007). During the identification of ferroptosis, there were two important chemical probes. Ferroptosis inducers, erastin, and RSL3, were discovered in a phenotypic small molecule-screening study (Dolma et al., 2003; Yang and Stockwell, 2008). Erastin, a synthetic compound, was capable of inducing non-apoptotic cell death to selectively kill HRAS-mutant engineered cancer cells, and in this process, there was no evidence of caspase activation or apoptotic hallmarks (Dolma et al., 2003; Yagoda et al., 2007). Another compound was RSL3, found in 2008, and capable of triggering a similar form of non-apoptotic and iron-dependent oxidative cell death (Yang and Stockwell, 2008). This erastin- and RSL3-induced cell death did not exhibit the morphological or biochemical features of apoptosis, and inhibition of necroptosis or autophagy had no effect on this mode of cell death (Wolpaw et al., 2011; Dixon et al., 2012; Yang et al., 2014). However, this manner of cell death could be prevented by the iron chelator, DFO, and antioxidants (e.g., Vitamin E) (Dolma et al., 2003; Yagoda et al., 2007; Yang and Stockwell, 2008). Therefore, the term "ferroptosis" was first proposed in 2012 to describe this novel iron-dependent non-apoptotic cell death (Dixon et al., 2012). Hallmark contributions of ferroptosis were well-displayed by Hirschhorn and Stockwell (2019) and Li J. et al. (2020) [for review see Hirschhorn and Stockwell (2019); Li J. et al. (2020)]. Hadian and Stockwell (2020) drew a SnapShot to provide an overview of ferroptosis-related pathways. Although the exact mechanisms of ferroptosis are still being explored, the initiation and execution of ferroptosis involve several biological processes, including lipid, GSH, and iron metabolism, as well as other regulatory processes (Dixon et al., 2012; Figure 1).

\section{Lipid Metabolism Related to Ferroptosis}

Lipid metabolism is closely linked to the regulation of ferroptosis. The accumulation of lipid peroxidation seems to be a key process in the execution phase, in which PUFAs play an important role (Stockwell et al., 2017; Wenzel et al., 2017; Yamada et al., 2020). Usually, free PUFAs, especially AA and AdA are esterified to membrane phospholipids [mainly PUFA-containing phosphatidylethanolamines (PEs)]. With the presence of two lipid-metabolic enzymes, ACSL4 and LPCAT3, these membrane phospholipids undergo oxidation to drive ferroptosis (Doll et al., 2017; Kagan et al., 2017). The knockout of ACSL4 or loss of LPCAT3 resulted in significant resistance of certain nonneuronal cells to ferroptosis (Dixon et al., 2015; Yuan et al., 2016; Doll et al., 2017; Kagan et al., 2017). Following the generation of AA/AdA-PE, activated LOXs catalyze AA/AdA-PE into proferroptotic lipid peroxidation AA/AdA-OOH-PE (Yang et al., 2016; Lei et al., 2019). The role of the LOXs in ferroptosis is also supported by a study indicating that genetic depletion 


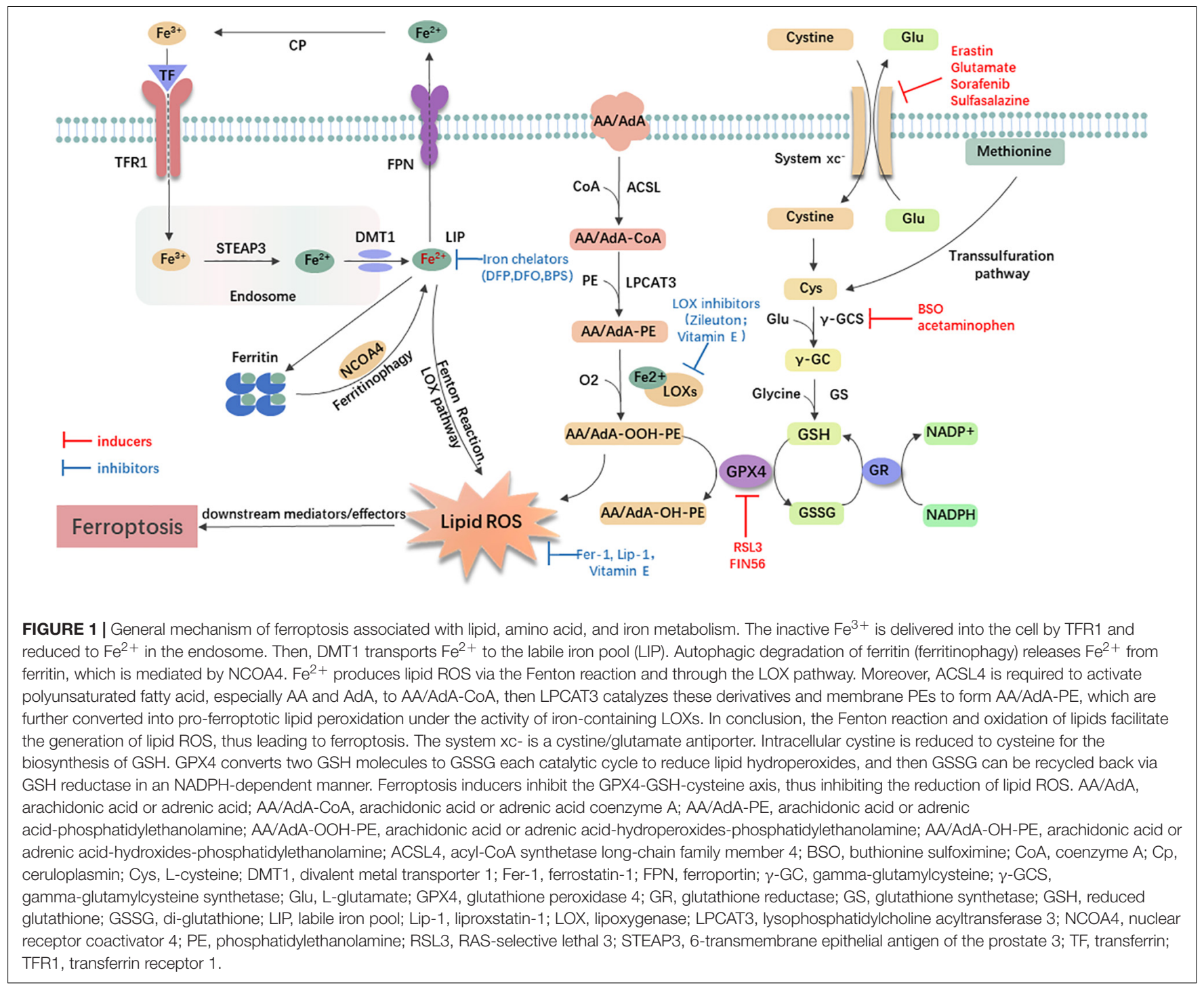

or inhibition of LOXs by inhibitors [e.g., zileuton (Liu et al., 2015) and Vitamin E hydroquinone (Hinman et al., 2018)] could protect against ferroptosis in some cell types (Seiler et al., 2008; Yang et al., 2016). Recently, PEBP1 was shown to bind 15LOX and alter the substrate specificity, changing it from free fatty acid to AA-PE, thereby promoting lipid oxidation (Wenzel et al., 2017). Furthermore, lipid peroxidation is thought to play a role in the final phase of ferroptosis, although the downstream mechanisms remain unclear (Lei et al., 2019). In one hypothesis, lipid peroxides may decompose into reactive toxic aldehydes, such as MDA or 4-HNEs. These decomposed substances react with proteins, nucleic acids, and membrane lipids to initiate ferroptosis (Domingues et al., 2013; Zhong and Yin, 2015). Dixon et al. also favored the hypothesis that showed that increased expression of AKRF1C genes could suppress ferroptosis by encoding aldoketoreductases to detoxify the end-products of lipid peroxidation (Dixon and Stockwell, 2014; Stockwell et al., 2017). As for inhibitors of lipid peroxidation, ferrostatins are the novel synthetic antioxidants that specifically trap lipid radicals and exert anti-ferroptotic function. Fer-1, the first-generation ferrostatin, prevents ferroptosis induced by erastin and RSL3 in HT1080 cells (Dixon et al., 2012). Lip-1 is another recently discovered ferroptosis inhibitor. It can prevent the accumulation of lipid ROS and inhibit erastin- or RSL3- induced ferroptosis in vitro (Friedmann Angeli et al., 2014). In conclusion, AA/AdArelated lipid metabolism can induce ferroptosis, and inhibiting LOXs or lipid peroxidation may have protective effects.

\section{Glutathione Metabolism Related to Ferroptosis}

Previous studies have identified that two major mechanisms, the Se-dependent GPX4-GSH-cysteine axis (Friedmann Angeli et al., 2014; Yang et al., 2014; Friedmann Angeli and Conrad, 2018; Ingold et al., 2018) and the FSP1-ubiquinone (CoQ10)-NAD(P)H pathway (Bersuker et al., 2019; Doll et al., 2019), were associated with lipid peroxidation and ferroptotic cell death. Additionally, the FSP1-CoQ10-NAD $(\mathrm{P}) \mathrm{H}$ pathway is a complementary system 
to the GPX4-GSH-cysteine axis for controlling ferroptosis. In this axis, key steps include cystine uptake via system $\mathrm{xc}$-, reduction of cystine to cysteine, GSH biosynthesis, and GPX4-mediated reduction of phospholipid hydroperoxides to lipid alcohols. During the process, the cystine/glutamate antiporter (system xc) which consists of the light-chain subunit $\mathrm{xCT}$ (SLC7A11) and the heavy-chain subunit CD98 (SLC3A2) exchanges intracellular glutamate for extracellular cystine at a ratio of 1:1. Cystine is then reduced to cysteine for GSH synthesis [for review see Xie et al. (2016)]. In this regard, several agents [e.g., glutamate and erastin (Dixon et al., 2012), sulfasalazine (Gout et al., 2001), and sorafenib (Dixon et al., 2014)] can inhibit the system xc- to cause the decreased acquisition of precursors and GSH depletion, ultimately leading to ferroptosis. Other agents, including BSO (Sun et al., 2018) and acetaminophen (Lorincz et al., 2015), were observed directly blocking GSH synthesis. Conversely, ferroptosis induced by cystine deprivation can be reversed by reagents that increase the level of intracellular cysteine/cystine. For example, an in vitro study showed that when in the presence of $\beta$-mercaptoethanol, the cells were able to constantly utilize cystine through a mixed disulfide of $\beta$-mercaptoethanol and cysteine (Ishii et al., 1981). In addition, the loss of cysteinyltRNA synthetase, as Hayano et al. (2016) indicated, could trigger the transsulfuration pathway and lead to inhibition of ferroptosis induced by cystine deprivation.

Glutathione peroxidases 4 is a type of selenoprotein that contains one selenocysteine at the active site and seven cysteines. It plays an important role in regulating ferroptosis, and its inhibition promotes ferroptosis (Yang et al., 2016). Regarded as the only GPX that can eliminate biomembrane lipid peroxidation, GPX4 has a unique ability in ferroptosis. It is capable of reducing the toxic, membranous lipid hydroperoxides into non-toxic lipid alcohols (Brigelius-Flohé and Maiorino, 2013; Yang et al., 2014). Increasing GPX4 has been shown to be beneficial in many models of disease by inhibiting ferroptosis (Lan et al., 2020; Shen et al., 2020). However, knockdown or inactivation of GPX4 contributes to the accumulation of lipid peroxidation and initiation of ferroptosis (Park et al., 2019; Ye et al., 2020). For example, RSL3 directly inactivated GPX4 by covalently binding to selenocysteine to trigger ferroptosis (Yang et al., 2014, 2016), and FIN56 promoted degradation of GPX4 (Shimada et al., 2016).

\section{Iron Metabolism Related to Ferroptosis}

Besides lipid and GSH metabolism, the essential trace element for life, iron, is indispensable for the execution of ferroptosis (Dixon and Stockwell, 2014). The circulating $\mathrm{Fe}^{3+}$ and TF complex are endocytosed into cells by the membrane protein transferrin receptor 1 (TFR1). In the endosome, $\mathrm{Fe}^{3+}$ is reduced to $\mathrm{Fe}^{2+}$ by STEAP3, and $\mathrm{Fe}^{2+}$ is then released into unstable iron pools mediated by DMT1, or stored in ferritin, which is composed of FTL and FTH1 (Yang and Stockwell, 2008; Dixon et al., 2012). Excessive $\mathrm{Fe}^{2+}$ is exported through the membrane protein FPN and oxidized by ferroxidases, such as ceruloplasmin (Bogdan et al., 2016; Shang et al., 2020). In this process, iron accumulation (Shang et al., 2020) and administration of iron-bound, rather than iron-free $\mathrm{TF}$, promote erastin-induced ferroptosis (Gao et al., 2015). On the contrary, using some iron chelators [e.g., DFP (Wu et al., 2020), DFO (Wu et al., 2018; Chen et al., 2020), and BPS (Codenotti et al., 2018)] may suppress ferroptosis and provide a potential therapeutic approach for diseases. In fact, there are some iron-chelating agents under clinical development for the treatment of cancers [for review see Brown et al. (2020)]. Moreover, inhibition of the IREB2 increases the expression of FTL and FTH1, thus decreasing sensitivity to ferroptosis (Gammella et al., 2015).

Although the importance of intracellular free iron in ferroptosis is confirmed, the regulatory mechanism of iron remains unknown. To date, the evidence has shown that the non-enzymatic free radical chain reaction involving Fenton Chemistry, in which $\mathrm{Fe}^{2+}$ is converted to $\mathrm{Fe}^{3+}$ with increased ROS (Winterbourn, 1995; He et al., 2020), and enzymatic processes (most notably the lipoxygenase pathway, LOXs), contributed to the formation of lipid peroxides in ferroptosis. Moreover, iron may promote ferroptosis through other irondependent enzymes, such as HIF-PHDs (Siddiq et al., 2009). Therefore, iron metabolism is one of the mechanisms of ferroptosis, and utilizing iron chelators to decrease iron may be useful for treating diseases.

\section{THE ROLE AND MECHANISM OF FERROPTOSIS IN ACUTE CNS INJURIES}

As described above, ferroptosis is an iron-dependent cell death that involves abnormal metabolism of lipids, GSH, and iron. The methods of measurement in evaluating ferroptosis in diverse diseases mainly depend on monitoring the levels of iron and lipid peroxidation, the activity of GPX4, as well as the ability of ferroptosis inhibitors (e.g., iron chelators, LOX inhibitors, and ferrostatins) to reduce cell death [for review see Xie et al. (2016)]. Observations of typical morphological features under a TEM also contribute to the distinguishing characteristics of ferroptosis compared to other cell deaths, both in vitro and vivo (Friedmann Angeli et al., 2014; Alim et al., 2019; Li et al., 2019d). Recently, numerous studies have confirmed the hypothesis of ferroptosis in the pathophysiology of acute CNS injuries, including stroke (Alim et al., 2019; Guan et al., 2019), TBI (Kenny et al., 2019; Xiao et al., 2019; Xie et al., 2019), and SCI (Dinc et al., 2013; Hu et al., 2017). More studies are included in the following text and Figure 2 is a brief summary of ferroptosis in acute CNS injuries.

\section{The Role and Mechanism of Ferroptosis in Ischemic Stroke}

Ischemic stroke occurs when the blood flow to a certain portion of the brain is obstructed secondary to occlusion of cerebral arteries. The following deprivation of oxygen and energy triggers an ischemic cascade, such as OS and inflammation, resulting in neuronal excitotoxicity and cell death (Khoshnam et al., 2017; Li et al., 2019a; Zhang K. et al., 2019). Before ferroptosis was defined, iron accumulation [for review see Selim and Ratan (2004)] had been found in lesioned regions, such as the basal ganglia and the hippocampal area of the brain, and iron overload exaggerated neuronal damage during reperfusion (Dietrich and Bradley, 1988; 


\section{Ischemic Stroke}

- Increased iron accumulation in lesioned regions of animals and patients

- Increased lipid peroxidation with reduced GSH levels in ischemic animal brain

- Attenuated ischemic-reperfusion injury in MCAO mice by Fer-1 and Lip-1

Traumatic Brain Injury

- Increased iron levels around impaired tissue as early as 3 days after TBI

- Increased 15-LOX products with decreased GPX4 levels in injured cortex and hippocampus

- Reduced iron accumulation and neuronal degeneration by Fer-1 in mice after $\mathrm{CCl}$

\section{Intracerebral Hemorrhage}

- Increased iron-handling proteins and transferrin receptor in rat brain after $\mathrm{ICH}$

- Reduced GPX4 levels associated with exacerbated brain injury after $\mathrm{ICH}$ in vivo

- Reduced neuronal death and improved neurologic function by Fer-1 in ICH model

\section{Ferroptósis}

Spinal Cord Injury

- Increased iron and accumulated ROS at the injury site in rat $\mathrm{SCl}$ models

- Induced motor neuron degeneration and paralysis by GPX4 ablation

- Improved neuronal survival and locomotor recovery by $\mathrm{SRS} 16-86$ in rat $\mathrm{SCl}$ models

FIGURE 2 | An overview of ferroptosis-associated mechanism and potential therapy in acute CNS injuries.

Kondo et al., 1995; Lipscomb et al., 1998; Park et al., 2011). In MCAO animals, the iron intake was positively associated with the infarct volume (Castellanos et al., 2002; García-Yébenes et al., 2012). Consistently, one in vitro study demonstrated that holo-transferrin increased ROS production, and caused neuronal cell death induced by deprivation of oxygen and glucose (DeGregorio-Rocasolano et al., 2018). The experimental results also illustrated that administration of exogenous apotransferrin reduced brain damage and improved neurological outcomes with decreased lipid peroxidation, supporting the involvement of ferroptosis in ischemia (DeGregorio-Rocasolano et al., 2018). What's more, the iron levels in the brain increased as humans age (Ward et al., 2014), which may exacerbate ischemic stroke. Recently, the tau-iron interaction has been proposed as an effective modulator of ferroptosis in ischemic stroke. The tau knockout mice were found to have increased protection from ferroptotic cell death following I/R injury, and the benefit of tau knockout was reinstated in older mice using iron-targeting interventions (Tuo et al., 2017). In this regard, iron chelation therapy reduced ischemic damage and improved outcome in mammals after ischemic stroke (Freret et al., 2006; Hanson et al., 2009). Consistently, Speer et al. (2013) found that the iron-dependent HIF-PHDs served as a target of metal chelators in ferroptosis, and the administration of iron chelators could inhibit HIF-PHDs, rather than suppress Fenton's Reaction or ROS production, providing beneficial effects on subjects.

Additionally, other ferroptosis-associated mechanisms, such as LOXs-mediated pathology (Yang et al., 2016) and the GPX4GSH-cysteine axis (Cho et al., 2007; Guan et al., 2019), were found to be involved in brain ischemia. MDA, a marker of oxidized lipids, was noticeably elevated, and this change correlated with increased activity of LOXs in an ischemic animal brain (Yigitkanli et al., 2013; Guan et al., 2019). Treatment with 12/15-LOX inhibitor (ML351) was shown to reduce infarct sizes and reperfusion damage in a mouse model (Rai et al., 2014). Moreover, Tuo et al. (2017) observed that brain damage was significantly attenuated by ferroptosis inhibitors, Lip-1, and Fer1, in an MCAO model. As for the GPX4-GSH-cysteine axis, various groups provide direct evidence supporting that inhibition of system xc- induces ferroptosis and aggravates ischemia. Lan et al. (2020) found that acute cerebral ischemia-induced neuronal ferroptosis and treatment with Naotaifang increased the expression levels of xCT, GPX4 and GSH, and the number of Nissl bodies in MCAO rats. These data suggested that Naotaifang may rescue ischemic stroke by inhibiting ferroptosis through the xCT/GPX4 pathways (Lan et al., 2020). Huang et al. (2019) also observed that inhibition of system xc- with erastin aggravated ferroptosis and augmenter of liver regeneration protected the kidney from ischemia-reperfusion injury in ferroptosis through GSH/GPX system. Guan et al. (2019) and Cho et al. (2007) identified reduced levels of GSH and decreased activities of GPX4 in ischemia. However, many researchers hold opposing views and state that activated system xc- can exacerbate ischemic cerebral injury due to increased glutamate. In their studies, $\mathrm{xCT}$ was expressed in significant concentrations in astrocytes in the mouse brain (Jackman et al., 2012; Thorn et al., 2015; Ottestad-Hansen et al., 2018). Increased activity of system xc(Soria et al., 2014) promoted the release of glutamate which may contribute to excitotoxicity in pathological situations (e.g., oxygen and glucose deprivation), leading to neuronal death 
(Thorn et al., 2015; Ottestad-Hansen et al., 2018). Hsieh et al. (2017) used both in vitro and in vivo models to reveal that HIF$1 \alpha$ triggered long-lasting glutamate excitotoxicity via activation of system xc- dependent glutamate outflow. HIF-1 $\alpha$ conditional knockout mouse had reduced extracellular glutamate in cerebral ischemia-reperfusion, suggesting that system xc- was a promising therapeutic target (Hsieh et al., 2017). Therefore, inhibition of system xc- can induce ferroptosis to promote neuronal death due to GSH depletion and activation of system xc- can also increase neuronal death because of glutamate-associated excitotoxicity. Whether induction of system xc- activity is beneficial or detrimental might depend on the pathway of induction and whether inhibition of system xc-or induction of $\mathrm{xCT}$ is the more promising neuroprotective strategy remains to be explored.

Other studies have confirmed the benefits of the necroptosis inhibitor, necrostatin-1, indicating that alternative forms of regulated cell death were involved in ischemic brain injury (Degterev et al., 2005). However, necrostatin-1 was later found to protect against ferroptosis through an unknown target (Friedmann Angeli et al., 2014). These results suggest that there is the direct involvement of ferroptosis in the pathogenesis of ischemic stroke. What about ferroptosis in hemorrhagic stroke?

\section{The Role and Mechanism of Ferroptosis in $\mathrm{ICH}$}

After ICH, there is a consequent physical disruption of the neurovascular architecture due to the mass effects and elevated pressure surrounding hemorrhagic sites, inducing primary brain injury. Subsequently, iron accumulates as a result of the degradation of $\mathrm{Hb}$ and its metabolite, hemin, which contributes to SBI (Hu et al., 2016). Previous data have identified multiple forms of cell death after ICH, including necrosis, apoptosis, and autophagy (Qureshi et al., 2001, 2003; Wang et al., 2015; Li et al., 2018). To date, multiple laboratories have provided converging lines of evidence that support the role of ferroptosis in $\mathrm{ICH}$ with the presence of observed molecular markers and morphological features (Li et al., 2017; Zille et al., 2017; Zhang et al., 2018; Alim et al., 2019), and the underlying mechanisms of ferroptosis in ICH are analogous to those of ischemic stroke. It was identified that iron overload stimulated neuronal ferroptosis, which aggravated brain damage (Wu et al., 2003, 2011). Besides, as one of the major upstream regulators of ferroptosis, GPX4 inactivation also contributes to ICH (Forcina and Dixon, 2019). It was found that levels of GPX4 were reduced and brain injury was exacerbated in a rat model of ICH induced by autologous blood injection, whereas overexpression of GPX4 was able to alleviate SBI and improve neurological outcomes (Zhang et al., 2018). Li et al. (2017) also indicated that administration of Fer1 reduced $\mathrm{Hb}$-induced cell death and iron deposition, prevented impairment of GPX4 activity in vitro, and improved neurologic function in collagenase-induced ICH models.

Many recent studies have suggested potential approaches to reduce brain damage. Zille et al. (2017) revealed that several ferroptosis inhibitors, including Fer-1, DFO, Trolox (a lipid peroxidation inhibitor), and NAC (a cell-permeable cysteine analog), were able to alleviate $\mathrm{Hb}$ - and hemin-induced cell death in vitro. Alim et al. (2019) also supported the role of Fer-1 by showing that inhibition of ferroptosis by Fer-1 exerted a longterm cerebroprotective effect in in vitro and in vivo ICH models. Dharmalingam et al. (2020) synthesized a multifunctional nanoparticle that protected cells from both senescence and ferroptosis, leading to a reduction of hemin/iron-induced toxicity in experimental ICH. In addition, Karuppagounder et al. (2018) found that ALOX5 inhibition could protect against ICH- or hemin-induced ferroptosis in vivo following $\mathrm{ICH}$.

Furthermore, the role of ferroptosis in $\mathrm{ICH}$ is supported by altered levels of other ferroptosis-related molecules. For example, phospho-ERK1/2, regarded as a molecular feature of ferroptosis (Yagoda et al., 2007), was significantly increased in mice with ICH, but the MEK inhibitor, U0126, inhibited this type of cell death (Zille et al., 2017). In addition, the expression levels of PTGS2 were also significantly increased in in vitro and in vivo ICH models (Li et al., 2017; Alim et al., 2019). Moreover, PTGS2 has been revealed as part of the downstream signaling pathway of ferroptosis in cancer cells (Yang et al., 2014). Notably, a gene product of PTGS2, known as COX-2, was substantially increased in neurons after $\mathrm{ICH}$, and treatment with Fer- 1 could reduce its expression and $\mathrm{ICH}$-induced SBI, implying that COX-2 might be used as a biomarker of ferroptosis (Zhao et al., 2007; Li et al., 2017; Alim et al., 2019). Thus far, there is little evidence that shows the relationship between ferroptosis and subarachnoid hemorrhage. More studies are warranted to investigate this promising topic.

\section{The Role and Mechanism of Ferroptosis in TBI}

The previous literature has shown that TBI shares many mechanisms (e.g., OS, inflammation, mitochondrial dysfunction, and neuronal cell death) with stroke (Blennow et al., 2016). In addition to these mechanisms, multiple studies have demonstrated that ferroptosis may contribute to the neuronal cell death and functional outcome in TBI (Ayton et al., 2014; Stockwell et al., 2017). The altered levels of various ferroptosis biomarkers provide evidence of ferroptosis in TBI. Studies have detected elevated iron concentrations around the impaired tissue as early as 3 days after injury, occurring in adult and aged mice models of controlled CCI (Portbury et al., 2016, 2017; Xie et al., 2019). The evidence also suggested that increased iron accumulation was negatively associated with cognitive outcomes in chronic TBI patients ( $\mathrm{Lu}$ et al., 2015), while iron chelators exhibited neuroprotective effects by diminishing iron-mediated brain damage (Zhang et al., 2013; Khalaf et al., 2018). According to recent studies, ferroptosis was identified in TBI through the detection of ferroptosis-associated molecules, such as 15-LOX and GPX4. For instance, there were enhanced levels of 15HpETE-PE and 15-LOX2 in the injured cortex and ipsilateral hippocampus, and decreased levels of GPX4 in a pediatric rat CCI model, suggesting that ferroptosis might occur within the first hour after TBI (Wenzel et al., 2017). Researchers also showed a preponderance of 15-LOX products in CCI-injured adult mice, and increased ACSL4 and 15-LOX2 expression in TBI, when compared with naive groups (Kenny et al., 2019). 
Moreover, numerous experimental and clinical studies observed the increased levels of MDA and 4-HNE in either the injured brain or serum following TBI (Hall et al., 2004; Readnower et al., 2010; Lorente et al., 2015; Xiao et al., 2019; Xie et al., 2019). As for the morphological features, Xie et al. (2019) first verifiably identified the ferroptotic features around brain injury lesions of TBI models at 3 days after CCI. As ferroptosis was shown to participate in TBI by the above work, inhibiting ferroptosis may be useful in treating TBI. For example, treatment with Fer1 significantly diminished iron accumulation, reduced neuronal cell death, and attenuated neuronal degeneration (Kenny et al., 2019; Xie et al., 2019). More details regarding therapy can be found in the next section.

\section{The Role and Mechanism of Ferroptosis in SCl}

In traumatic SCI, the primary injury causes immediate cellular damage and initiates a continuous secondary injury cascade to induce ischemia, inflammation, and cell death [for review see Ahuja et al. (2017)]. Notably, following the rupture of the bloodspinal cord barrier and blood vessels, hemorrhage occurs in the acute phase of SCI and may last for days (Tran et al., 2018). Like other acute CNS diseases, ferroptosis occurs in SCI, and is accompanied by increased iron and accumulated ROS at the site of injury (Liu et al., 2011; Visavadiya et al., 2016; Hao et al., 2017), as well as excessive lipid peroxidation (Dinc et al., 2013; $\mathrm{Hu}$ et al., 2017). This phenomenon is more apparent during the first several hours (Liu et al., 2004). In adult mouse models, Chen et al. (2015) observed that conditional ablation of Gpx4 in neurons could induce motor neuron degeneration and cause rapid paralysis, but this result was delayed by supplementation with vitamin E, suggesting that ferroptosis accelerated SCI. Therefore, anti-ferroptotic seems to have potential in SCI, though there are few studies. Feng et al. (2019) established a rat model of DFO and confirmed the positive role of DFO in treating SCI. In the DFO group, there were lower iron concentrations, markedly increased GPX4 expression, and increased neuronal survival (Feng et al., 2019). In the study conducted by Zhang Y. et al. (2019) treatment with the third-generation ferrostatin, SRS 16-86, increased neuronal survival and promoted locomotor recovery in the SCI model, providing potential therapeutic strategies for SCI. Indeed, it is well-known that the excitotoxicity caused by glutamate accumulation preceded neuronal death and reuptake failure of astrocytes, and also induced ferroptotic cell death to stimulate secondary injury after SCI (Dixon et al., 2014; Ahuja et al., 2017). The relationship between ferroptosis or excitotoxicity in SCI requires further studies.

\section{POTENTIAL AND EMERGING THERAPY TARGETING FERROPTOSIS IN ACUTE CNS INJURIES}

As ferroptosis may be a significant pathogenic pathway in acute CNS injuries, its therapeutic potential should be taken into consideration. Ferroptosis inhibitors (including iron chelators, ferrostatins, liproxstatins, LOX inhibitors, and antioxidants) may prevent iron accumulation or lipid peroxidation, thus offering therapeutic options for treating acute CNS injuries (Table 1).

\section{Targeting Ferroptosis Therapy in Ischemic Stroke}

The mainstay of treatment for acute ischemic stroke is rapid recanalization by mechanical thrombectomy or recombinant tissue plasminogen activator, the only approved thrombolytic agent. It is important to salvage the penumbra, which surrounds the region of the infarct and promotes functional recovery. However, the overall efficacy is limited due to the narrow window of opportunity (Sandercock et al., 2012), but even after timely recanalization, infarct volume often continues to increase in I/R injury (Nour et al., 2013). As previous methods have failed in clinical use, such as blocking excitotoxicity, the role of ferroptosis has been highlighted (Khoshnam et al., 2017; Tuo et al., 2017), and new therapeutic approaches targeting ferroptosis or combined therapies are highly desirable.

As mentioned above, Lip-1 and Fer-1 are both compounds with specific anti-ferroptotic activity. Intranasal administration of Lip-1 and Fer-1, either immediately or $6 \mathrm{~h}$ after reperfusion, significantly reduced neuronal damage and functional deficits in MCAO mice, indicating the possible translational value of special exogenous ferroptosis inhibitors (Tuo et al., 2017).

In addition, CoQ10 is an endogenous lipid-soluble antioxidant with established efficacy in suppressing the initiation and amplification of lipid peroxidation (Morris et al., 2013; Viswanathan et al., 2017), presenting a promising candidate for ferroptosis inhibition. Intriguingly, in vivo studies have reported that oral CoQ10 administration markedly improved neurological outcomes in both rat MCAO models and acute ischemic stroke patients (Ramezani et al., 2018; Nasoohi et al., 2019). This neuroprotective benefit of CoQ10 was associated with its antiapoptotic effect, as the levels of peroxidation products were not altered (Nasoohi et al., 2019). The authors attributed this to a relatively higher dose and multiple potential mechanisms of CoQ10. Of note, it is worth considering whether inhibition of ferroptosis is involved.

Recently, Guan et al. (2019) found that carvacrol, a plantderived monoterpenic phenol, inhibited hippocampal neuronal damage and reduced functional deficits in gerbils following I/R injury. Furthermore, treatment with carvacrol $(100 \mathrm{mg} / \mathrm{kg}$, intraperitoneally) for two consecutive weeks after reperfusion was associated with decreased ROS, reduced iron overload, and increased levels of GPX4, suggesting a possible neuroprotective role of carvacrol via ferroptosis inhibition (Guan et al., 2019). Carvacrol is thought to easily cross the BBB because of the small molecular weight and the lipophilic profile (Savelev et al., 2004). A previous study has proven the benefits of carvacrol when administered intraperitoneally at $2 \mathrm{~h}$ after reperfusion. When administered intracerebroventricularly, the treatment window was prolonged to $6 \mathrm{~h}$ (Yu et al., 2012). When administered safely, carvacrol may be regarded as a potential therapeutic agent.

Edaravone is an effective radical scavenger that inhibits lipid oxidation by scavenging chain-initiating water-soluble radicals 
TABLE 1 | Ferroptosis-associated drugs in treating the acute CNS injuries.

\begin{tabular}{|c|c|c|c|c|}
\hline Disease & Drug & Type & Administration Route & Function and Mechanism \\
\hline \multirow[t]{8}{*}{$\begin{array}{l}\text { Ischemic } \\
\text { stroke }\end{array}$} & $\begin{array}{l}\text { Liproxstatin-1 } \\
(\text { Lip-1) }\end{array}$ & $\begin{array}{l}\text { Lipid peroxides } \\
\text { inhibitor }\end{array}$ & Intranasal & $\begin{array}{l}\text { Attenuated motor function deficits, cognitive impairment; } \\
\text { improved neuroscores; reduced infarct volumes in middle } \\
\text { cerebral artery occlusion (MACO) mice. }\end{array}$ \\
\hline & Ferrostatin-1 (Fer-1) & $\begin{array}{l}\text { Lipid peroxides } \\
\text { inhibitor }\end{array}$ & Intranasal & $\begin{array}{l}\text { Attenuated neurological deficits and infarct volumes in MACO } \\
\text { mice. }\end{array}$ \\
\hline & ML351 & $\begin{array}{l}\text { Inhibitor of } \\
\text { 15-lipoxygenase-1 }\end{array}$ & Intravenous & $\begin{array}{l}\text { Reduced neurological impairment and infarct volume in MACO } \\
\text { mice. }\end{array}$ \\
\hline & $\begin{array}{l}\text { Amyloid precursor } \\
\text { protein ectodomain }\end{array}$ & $\begin{array}{l}\text { Protein stabilizing } \\
\text { ferroportin to export } \\
\text { iron }\end{array}$ & Intravenous & $\begin{array}{l}\text { Improved neuroscores and infarct volume; prevented iron } \\
\text { accumulation in the lesioned hemisphere in MACO mice. }\end{array}$ \\
\hline & Ceruloplasmin & $\begin{array}{l}\text { Copper regulating } \\
\text { iron-mediated } \\
\text { transport }\end{array}$ & Intraperitoneal & $\begin{array}{l}\text { Suppressed ischemia-induced hippocampal iron elevation in } \\
\text { the lesioned hemisphere in MACO mice. }\end{array}$ \\
\hline & Carvacrol & $\begin{array}{l}\text { Monoterpenic } \\
\text { phenol }\end{array}$ & Intraperitoneal & $\begin{array}{l}\text { Reduced neuronal cell death, increased GPx4 expression in } \\
\text { gerbils I/R hippocampal neurons (in vitro); decreased the level } \\
\text { of lipid peroxide and MDA, TFR, increased the Fpn1 } \\
\text { expression; alleviated neuronal degeneration and memory } \\
\text { deficits in I/R gerbils. }\end{array}$ \\
\hline & Deferoxamine & Iron chelator & Intraperitoneal & Suppressed the level of MDA. \\
\hline & Edaravone & $\begin{array}{l}\text { Free radical } \\
\text { scavenger; } \mathbf{A} \\
\text { clinically } \\
\text { approved drug } \\
\text { for treating acute }\end{array}$ & Not applicable & $\begin{array}{l}\text { Suppressed the accumulation of lipid peroxidation and ROS } \\
\text { production; inhibited ferroptosis induced by cystine deprivation, } \\
\text { erastin and RSL3 by scavenging radical species in } \\
\text { non-neuronal cells (in vitro). }\end{array}$ \\
\hline
\end{tabular}

Tat-linked SelP ischemic stroke

Peptide

$\mathrm{ICH}$

Ferrostatin-1
BBB-permeable

peptide containing selenocysteine

Lipid peroxides inhibitor
Intraperitoneal

Intracerebroventricular or intraperitoneal

$\begin{array}{lll}\text { Liproxstatin-1 } & \begin{array}{l}\text { Lipid peroxides } \\ \text { inhibitor }\end{array} & \text { Intraperitoneal } \\ \text { Zileuton/BW } & \text { Arachidonate } & \text { Not applicable } \\ \text { B70/BW A4C } & \text { 5-lipoxygenase } & \\ & \text { (ALOX5) inhibitors } & \\ \text { Compound 968 } & \text { Glutaminase } & \text { Intraperitoneal } \\ & \text { inhibitor } & \\ \text { Deferoxamine } & \text { Iron chelator } & \\ \text { N-acetylcysteine } & \text { Glutathione } & \text { Intraperitoneal } \\ \text { (NAC) } & \text { prodrug; } & \\ & \text { Thiol-containing } & \\ & \text { redox modulatory } & \\ \text { Trolox } & \text { compound } & \\ & \text { Water soluble lipid } & \text { Not applicable } \\ & \text { peroxidation } & \\ \text { U0126 } & \text { inhibitor } & \\ & \text { Extracellular- } & \text { Not applicable } \\ & \text { signaling kinase 1/2 } & \\ \text { (-)-Epicatechin } & \text { Brain-permeable } & \text { Orally } \\ & \text { flavanol } & \end{array}$

Reduced infarct volume in rodent MCAO model.

Prevented lipid ROS, MDA and GPx activity deficit (in vitro); inhibited $\mathrm{Hb}$ /ferrous-induced and hemin/hemoglobin-induced neuronal death (in vitro); reduced iron deposition and lipid ROS; diminished injury volume; rescued degenerating neurons, and corrected neurologic deficit in collagenase-induced ICH model; suppressed the level of GPX4; alleviated neuronal dysfunction; moderated brain atrophy and exerted long-term neuroprotective effects in autologous blood infusion model of $\mathrm{ICH}$.

Inhibited $\mathrm{Hb}$-induced cell death; decreased neurologic deficits and lesion volume; rescued neuronal cells in collagenase-induced ICH model. Inhibited $\mathrm{Hb} /$ hemin-induced cell death (in vitro).

Decreased degenerating neurons.

Inhibited hemin/hemoglobin-induced neuronal death. Inhibited hemin/hemoglobin-induced neuronal death (in vitro); increased glutathione, deceased nuclear ALOX5-derived reactice lipid species, reduced neuronal death, improved functional recovery in collagenase-induced mouse model of $\mathrm{ICH}$.

Inhibited hemin/hemoglobin-induced neuronal death (in vitro).

Inhibited hemin/hemoglobin-induced neuronal death (in vitro).

Diminished heme oxygenase-1 expression and brain iron deposition via an Nrf2-independent pathway, reduced lesion volume and ameliorated neurologic deficits in collagenase/autologous blood/thrombi-induced ICH model. 
TABLE 1 | Continued

\begin{tabular}{|c|c|c|c|c|}
\hline Disease & Drug & Type & Administration Route & Function and Mechanism \\
\hline & $\begin{array}{l}\text { Loxothiazolidine-4- } \\
\text { carboxylate } \\
\text { (OTC) }\end{array}$ & Cysteine prodrug & Not applicable & Inhibited hemin-induced neuronal death (in vitro). \\
\hline & $\begin{array}{l}\text { Glutathione ethyl } \\
\text { ester }\end{array}$ & $\begin{array}{l}\text { Membrane } \\
\text { permeable form of } \\
\text { glutathione }\end{array}$ & Not applicable & Inhibited hemin-induced neuronal death (in vitro). \\
\hline & Tat SelPep & $\begin{array}{l}\text { BBB-permeable } \\
\text { peptide containing } \\
\text { selenocysteine }\end{array}$ & Intraperitoneal & $\begin{array}{l}\text { Increased GPX4 expression; prevented hemin-induced } \\
\text { ferroptosis and preserved cell bodies and neurites of neurons } \\
\text { (in vitro); unregulated transcriptional expression of GPX4; } \\
\text { inhibited cell death and improved function in } \\
\text { collagenase-induced ICH model. }\end{array}$ \\
\hline & Selenium & $\begin{array}{l}\text { Essential } \\
\text { micronutrient }\end{array}$ & Intracerebroventricular & $\begin{array}{l}\text { Diminished cell death and improved functional recovery in a } \\
\text { mouse model of } \mathrm{ICH} \text {. }\end{array}$ \\
\hline \multirow[t]{5}{*}{ TBI } & Ferrostatin-1 & $\begin{array}{l}\text { Lipid peroxides } \\
\text { inhibitor }\end{array}$ & Intracerebroventricular & $\begin{array}{l}\text { Reduced neuronal death in mechanical stretch-elicited TBI } \\
\text { model (in vitro); reduced iron accumulation, neuron } \\
\text { degeneration and lesion volume; ameliorated cognitive and } \\
\text { motor function deficits in the adult controlled cortical impact } \\
\text { injury (CCl) mouse model. }\end{array}$ \\
\hline & Triacsin C & $\begin{array}{l}\text { Acyl-CoA } \\
\text { synthetase } \\
\text { long-chain family } \\
\text { member } 4 \text { (ACSL4) } \\
\text { inhibitor }\end{array}$ & Not applicable & $\begin{array}{l}\text { Reduced neuronal cell death in mechanical stretch-elicited TBI } \\
\text { model (in vitro). }\end{array}$ \\
\hline & Liproxstatin-1 & $\begin{array}{l}\text { Lipid peroxides } \\
\text { inhibitor }\end{array}$ & Not applicable & $\begin{array}{l}\text { Reduced neuronal cell death in mechanical stretch-elicited TBI } \\
\text { model (in vitro). }\end{array}$ \\
\hline & Baicalein & $\begin{array}{l}\text { 12/15-lipoxygenase } \\
\text { inhibitor }\end{array}$ & Intraperitoneal & $\begin{array}{l}\text { Reduced neuronal cell death in mechanical stretch-elicited TBI } \\
\text { model (in vitro); attenuated phosphatidylethanolamine oxidation } \\
\text { and improved function in } \mathrm{CCl} \text { mouse model. }\end{array}$ \\
\hline & miR-212-5p agomir & MicroRNAs agomir & Intracerebroventricular & Improved memory and learning in $\mathrm{CCl}$ mice. \\
\hline \multirow[t]{2}{*}{$\mathrm{SCl}$} & Deferoxamine & Iron chelator & Intraperitoneal & $\begin{array}{l}\text { Increased xCT, GSH, and GPX4 levels; protected neurons and } \\
\text { promoted long-term functional recovery in rat contusion SCI } \\
\text { model. }\end{array}$ \\
\hline & SRS 16-86 & $\begin{array}{l}\text { Small molecule } \\
\text { ferroptosis specific } \\
\text { inhibitor }\end{array}$ & Intraperitoneal & $\begin{array}{l}\text { Upregulated GPX4, GSH and xCT levels; down-regulated the } \\
\text { expression of } 4 \mathrm{HNE} \text {; increased neuronal survival and promoted } \\
\text { functional recovery in rat contusion } \mathrm{SCl} \text { model. }\end{array}$ \\
\hline
\end{tabular}

and chain-carrying lipid peroxyl radicals due to its amphiphilicity (Watanabe et al., 2018). There are several papers describing its alleviatory effects on neurological symptoms in ischemia models, and its effective treatment window of at least $3 \mathrm{~h}$ after embolism (Nishi et al., 1989; Kawai et al., 1997; Lapchak and Zivin, 2009). In the clinical setting, the appropriate dosage and course of edaravone use for patients suffering from acute ischemic stroke include intravenous administration of $60 \mathrm{mg}$ daily for up to 14 days (Feng et al., 2011). Homma et al. (2019) recently indicated that edaravone participates in rescuing ferroptotic cell death induced by cystine deprivation, erastin, and RSL3 (Homma et al., 2019). In addition, edaravone was confirmed to suppress the accumulation of $\mathrm{Fe}^{2+}$ and lipid peroxidation in vitro, which are known as the metabolic characteristics of ferroptosis.

\section{Targeting Ferroptosis Therapy in ICH}

Currently, there are no proven medical or surgical treatments that substantially improve the neurological outcomes in patients with ICH because of multiple underlying mechanisms, including inflammation, excitotoxicity, and OS (Keep et al., 2012). As emerging studies suggest that ferroptosis is involved in SBI after
$\mathrm{ICH}$, and contributes to $80 \%$ of whole-cell death in vitro (Li et al., 2017; Zille et al., 2017), ferroptosis-based treatments could be highly considered.

Li et al. demonstrated the neuroprotective effects of Fer1 by striatum injection immediately after and by cerebral ventricular injection $2 \mathrm{~h}$ after collagenase-induced ICH [for review see Li et al. (2017)]. Intraperitoneal administration of Fer-1 (a 3-h delay and then once daily) in the autologous blood infusion model of ICH was also shown to improve longterm neurological function (Alim et al., 2019). Moreover, when combined with other inhibitors of either apoptosis or necrosis, Fer-1 was found to be more effective at reducing $\mathrm{Hb}$-induced cell death, which should be further investigated in in vivo models (Li et al., 2017).

Various evidence has shown that iron chelators reduce $\mathrm{Hb}$ and iron-induced neurotoxicity attenuates brain edema, and improve functional neurologic outcomes after ICH (Nakamura et al., 2004; Wu et al., 2012; Hatakeyama et al., 2013). A metaanalysis of 20 studies involving animal models of ICH revealed that DFO was neuroprotective, particularly when administered 2-4 h after ICH induction (Cui et al., 2015), whereas there 
remains a lack of conclusive clinical evidence regarding iron chelators (Zeng et al., 2018).

$\mathrm{N}$-acetylcysteine (Gilbert et al., 1991; Leslie et al., 1992; Varga et al., 1997) is an FDA-approved cysteine prodrug capable of regulating the activity of system xc- and the biosynthesis of GSH [for review see Berk et al. (2013)]. Interestingly, a recent study reported that systemic administration of NAC post-injury reduced neuronal death and improved behavior following ICH in mice (Karuppagounder et al., 2018). They further pointed out that NAC inhibited hemin- and ICHinduced ferroptosis by neutralizing nuclear ALOX5-derived toxic lipid species (Karuppagounder et al., 2018). This process relied on increased GSH and enhanced activity of GSH-dependent antioxidant enzymes. Considering the poor absorption of direct GSH administration and the insufficient capacity of GSH to cross the BBB (Witschi et al., 1992), NAC may be treated as an adjuvant therapy candidate capable of penetrating the $\mathrm{BBB}$ to enter the brain (Farr et al., 2003).

In addition, EC, a brain-permeable flavanol, was shown to reduce early brain injury and improve neurologic deficits in multiple experimental ICH models when administered orally at $3 \mathrm{~h}$ post-treatment and subsequent daily administration (Chang et al., 2014). The neuroprotective effects of EC were partially associated with decreased iron deposition and modulation of ferroptosis-related gene expression, indicating the possible ability of EC to inhibit ICH-induced ferroptotic cell death (Chang et al., 2014).

$\mathrm{Se}$ is indispensable for the ferroptosis-resistant function of GPX4 (Ingold et al., 2018). It was recently uncovered that Se could amplify an adaptive transcriptional program response to neuronal ferroptosis (Alim et al., 2019), making it a potential therapeutic strategy. Further studies discovered that injection of Se directly into the mouse cerebral ventricle following ICH was associated with elevated GPX4 levels, diminished ferroptotic death, as well as improved functional recovery. Moreover, the researchers developed a peptide (Tat SelPep), which contained a Tat transduction domain combined with selenoprotein P. Intraperitoneal injection of Tat SelPep showed similar effects compared to Se, but with reduced toxicity and a wider treatment window, with benefits shown even at $6 \mathrm{~h}$ post-injury (Alim et al., 2019).

\section{Targeting Ferroptosis Therapy in TBI}

When contemplating feasible treatments for TBI, researchers focus on secondary events, which cause delayed damage, to provide applicable therapeutic windows for interventions [for review see Lozano et al. (2015)]. Given that there are currently no effective treatments approved by clinical trials for TBI patients (Pearn et al., 2017), there exists a pressing need for developing more innovative methods, such as targeting ferroptotic cell death in a highly regulated manner. The ferroptosis signaling molecules can be prevented as a result of reducing $\mathrm{PE}$ oxidation by inhibiting the ability of 15LOX/PEBP1 complexes to produce 15-HpETE-PE, administrating 15LOX inhibitors, or augmenting the GPX4/GSH system to remove oxidized PE products (Wenzel et al., 2017; Kenny et al., 2019).
Baicalein is a polyphenolic antioxidant 12/15-LOX inhibitor and is well-known to exert neuroprotective effects in cerebral ischemia [for review see Liang et al. (2017)]. Recently, Kenny et al. (2019) demonstrated that baicalein decreased the accumulation of pro-ferroptotic $\mathrm{PE}$ oxidation, but not pro-apoptotic cardiolipin oxidation after CCI, indicating that the 15-LOX inhibitory effects of baicalein may have an anti-ferroptotic role in TBI. Several studies have also revealed a reduction of functional and histological damage with the immediate administration of baicalein post-injury (Chen et al., 2008; Kenny et al., 2019). With low levels of toxicity and the ability to cross the BBB (Tsai et al., 2002), baicalein offers great promise in clinical settings if the effect of delayed drug delivery is evaluated.

As mentioned above, NAC is a precursor for GSH, and it has been shown to confer antioxidant and neuroprotective effects after pre-clinical TBI (Eakin et al., 2014; Senol et al., 2014). As for adult patients, a double-blinded and placebo-controlled study indicated that supplementation of oral NAC had significant short-term benefits on neurological symptoms and sequelae resolution after blast-induced mild TBI (Hoffer et al., 2013). Due to the low bioavailability of NAC, the compound, NACA, was developed with increased membrane permeability, and its neuroprotection was associated with the activation of the Nrf2antioxidant response elements signaling pathway in a mouse model of TBI (Zhou et al., 2018). It is well-established that Nrf2 regulates $\mathrm{xCT}$ and GPX4, whose inhibition initiates ferroptosis and promotes target genes that mediate the antioxidant and iron metabolic status of cells (Zhou et al., 2018), suggesting another anti-ferroptotic mechanism of NACA.

In a mouse CCI model of TBI, Fer-1 treatment had been injected directly into the cerebral ventricle $0.5 \mathrm{~h}$ after injury, causing a reduction in neuronal death and other associated functional defects (Xie et al., 2019). However, more research should be implemented to uncover feasible drugdelivery methods.

Moreover, a recent study demonstrated the role of miR212-5p in suppressing ferroptosis after TBI, partially by targeting PTGS2 (Xiao et al., 2019). Further results showed that intracerebroventricular injection of miR-212-5p agomir improved spatial memory and learning in CCI mice, suggesting that miR-212-5p may serve as a potential ferroptosis inhibitor to be used in treating TBI. As previously discussed, the oxidation of AA/AdA-PE is a critical step in ferroptosis execution. Therefore, inhibition of ACSL (such as triacsin C and thiazolidinedione) and formation of AA/AdA-esterified PE may also protect against ferroptosis after TBI (Doll et al., 2017; Kagan et al., 2017; Kenny et al., 2019).

\section{Targeting Ferroptosis Therapy in SCl}

There are no neuroprotective or neurodegenerative strategies currently approved for acute traumatic SCI, but several are currently undergoing clinical trials (Badhiwala et al., 2018). The concept of "time is spine" is commonly applied in the management of patients with SCI. Since ferroptosis is likely involved in the acutes phases of SCI, therapies targeting ferroptosis are promising (Badhiwala et al., 2018; Zhang Y. et al., 2019). 
Targeting iron is one of the treatment strategies. The iron chelator, DFO, reportedly reduced iron accumulation and lipid peroxidation, while modulating the inflammatory response in SCI (Paterniti et al., 2010; Liu et al., 2011; Dinc et al., 2013; Hao et al., 2017). Experimental evidence indicated that DFO improved motor function recovery when injected intraperitoneally postSCI (Paterniti et al., 2010; Liu et al., 2011; Hao et al., 2017). Moreover, DFO showed neuroprotective effects comparable with methylprednisolone, an effective antioxidant agent that is contentious for the treatment of SCI because of harmful side effects (Dinc et al., 2013; Silva et al., 2014). However, oral treatment of deferasirox, another FDA-approved iron chelator, failed to remove iron from the injured spinal cord, but markedly depleted the systemic iron (Sauerbeck et al., 2013). Considering the detrimental side effects (e.g., anemia) and the absence of potent neuroprotection, systemic administration may not be the ideal approach of iron chelators (Grossman et al., 2012; Sauerbeck et al., 2013).

Besides, previous studies have demonstrated that NAC administration suppressed OS, attenuated neuroinflammation, and improved neuronal survival and neurological recovery following SCI in rodent models (Karalija et al., 2012, 2014; Guo et al., 2015). When administered immediately after SCI, NACA, an amide derivative of NAC, improved mitochondrial function, antioxidant GSH levels, and functional recovery in SCI mice (Patel et al., 2014). These two GSH precursors facilitate the biosynthesis of intracellular GSH. In addition, the GSH antioxidant system plays a pivotal role in the regulation of ferroptosis (Lv et al., 2019).

Recently, Li et al. (2019b) observed that CoQ10, a promising ferroptosis inhibitor previously mentioned, exerted protective effects by decreasing OS partly through activation of the Nrf-2 signaling pathway after SCI. Moreover, Nrf-2 is regarded as a significant mitigator of lipid peroxidation and ferroptosis [for review see Dodson et al. (2019)]. Furthermore, CoQ10 was shown to protect BMSCs from OS, and improved the therapeutic efficacy in combination with BMSC transplantation, suggesting a promising therapy for SCI (Li et al., 2019c).

Besides, post-injury intraperitoneal injection of SRS 16-86 proved to be more potent and stable than Fer-1. It also attenuated the ferroptotic mitochondrial morphology in damaged areas, and improved neurological deficits in SCI model, suggesting the role of ferroptosis-specific inhibitors in the treatment of SCI (Zhang Y. et al., 2019).

\section{DISCUSSION AND PERSPECTIVE: WILL FERROPTOSIS BE THE FUTURE DIRECTION?}

In this article, we primarily focus on the roles and therapeutic potential of ferroptosis in various acute CNS injury processes, including stroke, TBI, and SCI. Pharmacological effects of multiple inducers and inhibitors of ferroptosis lie at the intersection of lipid, amino acid, and iron metabolism. Although some progress has been made in ferroptosis, there are still controversial questions that have not been fully studied. First, the relationship between ferroptosis and other forms of cell death remains unknown. For example, p53 is an important regulator, both in apoptosis and ferroptosis, while autophagy plays a role in the process of ferroptosis via ferritinophagy. As ferroptosis is involved in acute CNS injuries complicated by necrosis, apoptosis, and autophagy, a head-to-head comparison of individual inhibitors or various combinations of inhibitors is required in further studies. Second, the special molecular markers (e.g., caspase activation for apoptosis or the autophagosome marker, LC3-II, for autophagy) for identifying ferroptosis are still lacking. While the increased mRNA levels of PTGS2 were found in cells undergoing ferroptosis, it did not affect ferroptosis progress (Yang et al., 2014). The specificity of PTGS2 expression or its gene product, COX-2, for ferroptosis needs to be explored in the context of different pathophysiologic processes. Actually, there is copious evidence for the role of COX-2 in several acute neurological disorders (e.g., ischemic and hemorrhagic strokes) (Gong et al., 2001; Tomimoto et al., 2002). The research of additional ferroptosis markers is of great importance for in vivo studies in the future. Moreover, the exact role of iron and the final molecular executor in ferroptosis remains unclear. Considering the complexity of the CNS, the biochemical regulation, as well as the sensitivity of ferroptosis in different cell types (neurons, astrocytes, microglia, or oligodendrocytes), also requires explication.

Potential treatment options targeting ferroptosis (e.g., iron chelators, ferrostatins, NAC, and CoQ10) have shown neuroprotective effects in acute CNS injuries. However, these benefits are largely based on animal models and have not yet translated into clinical application. Furthermore, studies are necessary to clarify the appropriate therapeutic window, clinically feasible routes of administration, and BBB penetration ability of anti-ferroptotic agents. Among the above-mentioned agents, edaravone is the only approved drug with proven clinical efficacy and safety, while others should be explored in further clinical studies. More in-depth and comprehensive research on ferroptosis should be conducted to develop therapeutic methods and eventually alleviate the burden of acute CNS injuries in the future.

\section{AUTHOR CONTRIBUTIONS}

All the authors participated in analyzing and discussing the literature, commenting on, and read and approved the final manuscript. AS and YC supervised the research, led the discussion, and wrote and revised the manuscript.

\section{FUNDING}

This work was funded by the National Natural Science Foundation of China (81701144, 81371433, and 81870916), and Major Science and Technology Project in the medical and health of Zhejiang Province (WKJ-ZJ-1615:2016149634). 


\section{REFERENCES}

Ahuja, C. S., Wilson, J. R., Nori, S., Kotter, M. R. N., Druschel, C., Curt, A., et al. (2017). Traumatic spinal cord injury. Nat. Rev. Dis. Primers 3:17018.

Alim, I., Caulfield, J. T., Chen, Y., Swarup, V., Geschwind, D. H., Ivanova, E., et al. (2019). Selenium drives a transcriptional adaptive program to block ferroptosis and treat stroke. Cell 177, 1262-1279.e25. doi: 10.1016/j.cell.2019.03.032

Ayton, S., Zhang, M., Roberts, B. R., Lam, L. Q., Lind, M., McLean, C., et al. (2014). Ceruloplasmin and $\beta$-amyloid precursor protein confer neuroprotection in traumatic brain injury and lower neuronal iron. Free Radic. Biol. Med. 69, 331-337. doi: 10.1016/j.freeradbiomed.2014.01.041

Badhiwala, J. H., Ahuja, C. S., and Fehlings, M. G. (2018). Time is spine: a review of translational advances in spinal cord injury. J. Neurosurg. Spine 30, 1-18. doi: 10.3171/2018.9.spine18682

Benjamin, E. J., Muntner, P., Alonso, A., Bittencourt, M. S., Callaway, C. W., Carson, A. P., et al. (2019). Heart disease and stroke statistics-2019 update: a report from the American Heart Association. Circulation 139, e56-e528.

Berk, M., Malhi, G. S., Gray, L. J., and Dean, O. M. (2013). The promise of $\mathrm{N}$-acetylcysteine in neuropsychiatry. Trends Pharmacol. Sci. 34, 167-177. doi: 10.1016/j.tips.2013.01.001

Bersuker, K., Hendricks, J. M., Li, Z., Magtanong, L., Ford, B., Tang, P. H., et al. (2019). The CoQ oxidoreductase FSP1 acts parallel to GPX4 to inhibit ferroptosis. Nature 575, 688-692. doi: 10.1038/s41586-019-1705-2

Blennow, K., Brody, D. L., Kochanek, P. M., Levin, H., McKee, A., Ribbers, G. M., et al. (2016). Traumatic brain injuries. Nat. Rev. Dis. Primers 2:16084.

Bogdan, A. R., Miyazawa, M., Hashimoto, K., and Tsuji, Y. (2016). Regulators of iron homeostasis: new players in metabolism, cell death, and disease. Trends Biochem. Sci. 41, 274-286. doi: 10.1016/j.tibs.2015.11.012

Brigelius-Flohé, R., and Maiorino, M. (2013). Glutathione peroxidases. Biochim. Biophys. Acta 1830, 3289-3303.

Brown, R. A. M., Richardson, K. L., Kabir, T. D., Trinder, D., Ganss, R., and Leedman, P. J. (2020). Altered iron metabolism and impact in cancer biology, metastasis, and immunology. Front. Oncol. 10:476. doi: 10.3389/fonc.2020. 00476

Castellanos, M., Puig, N., Carbonell, T., Castillo, J., Martinez, J., Rama, R., et al. (2002). Iron intake increases infarct volume after permanent middle cerebral artery occlusion in rats. Brain Res. 952, 1-6. doi: 10.1016/s0006-8993(02) 03179-7

Chamorro, A., Dirnagl, U., Urra, X., and Planas, A. M. (2016). Neuroprotection in acute stroke: targeting excitotoxicity, oxidative and nitrosative stress, and inflammation. Lancet Neurol. 15, 869-881. doi: 10.1016/s1474-4422(16)0 0114-9

Chang, C. F., Cho, S., and Wang, J. (2014). (-)-Epicatechin protects hemorrhagic brain via synergistic Nrf2 pathways. Ann. Clin. Transl. Neurol. 1, 258-271. doi: $10.1002 / \operatorname{acn} 3.54$

Chen, L., Hambright, W. S., Na, R., and Ran, Q. (2015). Ablation of the Ferroptosis inhibitor glutathione peroxidase 4 in neurons results in rapid motor neuron degeneration and paralysis. J. Biol. Chem. 290, 28097-28106. doi: 10.1074/jbc. m115.680090

Chen, S. F., Hsu, C. W., Huang, W. H., and Wang, J. Y. (2008). Post-injury baicalein improves histological and functional outcomes and reduces inflammatory cytokines after experimental traumatic brain injury. Br. J. Pharmacol. 155, 1279-1296. doi: 10.1038/bjp.2008.345

Chen, X., Li, D., Sun, H. Y., Wang, W. W., Wu, H., Kong, W., et al. (2020). Relieving ferroptosis may partially reverse neurodegeneration of the auditory cortex. FEBS J. [Epub ahead of print].

Cho, S., Szeto, H. H., Kim, E., Kim, H., Tolhurst, A. T., and Pinto, J. T. (2007). A novel cell-permeable antioxidant peptide, SS31, attenuates ischemic brain injury by down-regulating CD36. J. Biol. Chem. 282, 4634-4642. doi: 10.1074/ jbc.m609388200

Codenotti, S., Poli, M., Asperti, M., Zizioli, D., Marampon, F., and Fanzani, A. (2018). Cell growth potential drives ferroptosis susceptibility in rhabdomyosarcoma and myoblast cell lines. J. Cancer Res. Clin. Oncol. 144, 1717-1730. doi: 10.1007/s00432-018-2699-0

Cui, H.-J., He, H.-Y., Yang, A. L., Zhou, H.-J., Wang, C., Luo, J.-K., et al. (2015). Efficacy of deferoxamine in animal models of intracerebral hemorrhage: a systematic review and stratified meta-analysis. PLoS One 10:e0127256. doi: 10.1371/journal.pone.0127256
DeGregorio-Rocasolano, N., Marti-Sistac, O., Ponce, J., Castello-Ruiz, M., Millan, M., Guirao, V., et al. (2018). Iron-loaded transferrin (Tf) is detrimental whereas iron-free Tf confers protection against brain ischemia by modifying blood Tf saturation and subsequent neuronal damage. Redox Biol. 15, 143-158. doi: 10.1016/j.redox.2017.11.026

Degterev, A., Huang, Z., Boyce, M., Li, Y., Jagtap, P., Mizushima, N., et al. (2005). Chemical inhibitor of nonapoptotic cell death with therapeutic potential for ischemic brain injury. Nat. Chem. Biol. 1, 112-119. doi: 10.1038/nchembio711

Dharmalingam, P., Talakatta, G., Mitra, J., Wang, H., Derry, P. J., Nilewski, L. G., et al. (2020). Pervasive genomic damage in experimental intracerebral hemorrhage: therapeutic potential of a mechanistic-based carbon nanoparticle. ACS Nano 14, 2827-2846. doi: 10.1021/acsnano.9b05821

Dietrich, R. B., and Bradley, W. G. (1988). Iron accumulation in the basal ganglia following severe ischemic-anoxic insults in children. Radiology 168, 203-206. doi: 10.1148/radiology.168.1.3380958

Dinc, C., Iplikcioglu, A. C., Atabey, C., Eroglu, A., Topuz, K., Ipcioglu, O., et al. (2013). Comparison of deferoxamine and methylprednisolone: protective effect of pharmacological agents on lipid peroxidation in spinal cord injury in rats. Spine 38, E1649-E1655.

Dixon, S. J., Lemberg, K. M., Lamprecht, M. R., Skouta, R., Zaitsev, E. M., Gleason, C. E., et al. (2012). Ferroptosis: an iron-dependent form of nonapoptotic cell death. Cell 149, 1060-1072. doi: 10.1016/j.cell.2012.03.042

Dixon, S. J., Patel, D., Welsch, M., Skouta, R., Lee, E., Hayano, M., et al. (2014). Pharmacological inhibition of cystine-glutamate exchange induces endoplasmic reticulum stress and ferroptosis. Elife 3:e02523.

Dixon, S. J., and Stockwell, B. R. (2014). The role of iron and reactive oxygen species in cell death. Nat. Chem. Biol. 10, 9-17. doi: 10.1038/nchembio.1416

Dixon, S. J., Winter, G. E., Musavi, L. S., Lee, E. D., Snijder, B., Rebsamen, M., et al. (2015). Human haploid cell genetics reveals roles for lipid metabolism genes in nonapoptotic cell death. ACS Chem. Biol. 10, 1604-1609. doi: 10.1021/ acschembio.5b00245

Dodson, M., Castro-Portuguez, R., and Zhang, D. D. (2019). NRF2 plays a critical role in mitigating lipid peroxidation and ferroptosis. Redox Biol. 23:101107. doi: 10.1016/j.redox.2019.101107

Doll, S., Freitas, F. P., Shah, R., Aldrovandi, M., da Silva, M. C., Ingold, I., et al. (2019). FSP1 is a glutathione-independent ferroptosis suppressor. Nature 575, 693-698. doi: 10.1038/s41586-019-1707-0

Doll, S., Proneth, B., Tyurina, Y. Y., Panzilius, E., Kobayashi, S., Ingold, I., et al. (2017). ACSL4 dictates ferroptosis sensitivity by shaping cellular lipid composition. Nat. Chem. Biol. 13, 91-98. doi: 10.1038/nchembio. 2239

Dolma, S., Lessnick, S. L., Hahn, W. C., and Stockwell, B. R. (2003). Identification of genotype-selective antitumor agents using synthetic lethal chemical screening in engineered human tumor cells. Cancer Cell 3, 285-296. doi: 10.1016/s15356108(03)00050-3

Domingues, R. M., Domingues, P., Melo, T., érez-Sala, D. P., Reis, A., and Spickett, C. M. (2013). Spickett, lipoxidation adducts with peptides and proteins: deleterious modifications or signaling mechanisms? J. Proteom. 92, 110-131. doi: 10.1016/j.jprot.2013.06.004

Duan, J. L., Cui, J., Yang, Z. F., Guo, C., Cao, J. Y., Xi, M. M., et al. (2019). Neuroprotective effect of Apelin 13 on ischemic stroke by activating AMPK/GSK-3 beta/Nrf2 signaling. J. Neuroinflamm. 16:24.

Eakin, K., Baratz-Goldstein, R., Pick, C. G., Zindel, O., Balaban, C. D., Hoffer, M. E., et al. (2014). Efficacy of $\mathrm{N}$-acetyl cysteine in traumatic brain injury. PLoS One 9:e90617. doi: 10.1371/journal.pone.0090617

Farr, S. A., Poon, H. F., Dogrukol-Ak, D., Drake, J., Banks, W. A., Eyerman, E., et al. (2003). The antioxidants alpha-lipoic acid and $\mathrm{N}$-acetylcysteine reverse memory impairment and brain oxidative stress in aged SAMP8 mice. J. Neurochem. 84, 1173-1183. doi: 10.1046/j.1471-4159.2003.01580.x

Feng, S., Yang, Q., Liu, M., Li, W., Yuan, W., Zhang, S., et al. (2011). Edaravone for acute ischaemic stroke. Cochrane Database Syst Rev 12:CD007230.

Feng, S.-Q., Yao, X., Zhang, Y., Hao, J., Duan, H.-Q., Zhao, C.-X., et al. (2019). Deferoxamine promotes recovery of traumatic spinal cord injury by inhibiting ferroptosis. Neural. Regen. Res. 14, 532-541.

Forcina, G. C., and Dixon, S. J. (2019). GPX4 at the crossroads of lipid homeostasis and ferroptosis. Proteomics 19:e1800311.

Freret, T., Valable, S., Chazalviel, L., Saulnier, R., Mackenzie, E. T., Petit, E., et al. (2006). Delayed administration of deferoxamine reduces brain damage and 
promotes functional recovery after transient focal cerebral ischemia in the rat. Eur. J. Neurosci. 23, 1757-1765. doi: 10.1111/j.1460-9568.2006.04699.x

Friedmann Angeli, J. P., and Conrad, M. (2018). Selenium and GPX4, a vital symbiosis. Free Radic. Biol. Med. 127, 153-159. doi: 10.1016/j.freeradbiomed. 2018.03.001

Friedmann Angeli, J. P., Schneider, M., Proneth, B., Tyurina, Y. Y., Tyurin, V. A., Hammond, V. J., et al. (2014). Inactivation of the ferroptosis regulator Gpx4 triggers acute renal failure in mice. Nat. Cell. Biol. 16, 1180-1191. doi: 10.1038/ ncb3064

Gammella, E., Recalcati, S., Rybinska, I., Buratti, P., and Cairo, G. (2015). Ironinduced damage in cardiomyopathy: oxidative-dependent and independent mechanisms. Oxid. Med. Cell. Longev. 2015:230182.

Gangadhar, N. M., and Stockwell, B. R. (2007). Chemical genetic approaches to probing cell death. Curr. Opin. Chem. Biol. 11, 83-87. doi: 10.1016/j.cbpa.2006. 11.033

Gao, M., Monian, P., Quadri, N., Ramasamy, R., and Jiang, X. (2015). Glutaminolysis and transferrin regulate ferroptosis. Mol. Cell 59, 298-308. doi: 10.1016/j.molcel.2015.06.011

García-Yébenes, I., Sobrado, M., Moraga, A., Zarruk, J. G., Romera, V. G., Pradillo, J. M., et al. (2012). Iron overload, measured as serum ferritin, increases brain damage induced by focal ischemia and early reperfusion. Neurochem. Int. 61, 1364-1369. doi: 10.1016/j.neuint.2012.09.014

GBD (2016). Global, regional, and national burden of stroke, 1990-2016: a systematic analysis for the Global Burden of disease study 2016. Lancet Neurol. $18,439-458$.

GBD (2019). Global, regional, and national burden of traumatic brain injury and spinal cord injury, 1990-2016: a systematic analysis for the Global Burden of disease study 2016. Lancet Neurol. 18, 56-87.

Gilbert, K. R., Aizenman, E., and Reynolds, I. J. (1991). Oxidized glutathione modulates N-Methyl-D-aspartate-induced and depolarization-induced increases in intracellular $\mathrm{Ca} 2+$ in cultured rat forebrain neurons. Neurosci. Lett. 133, 11-14. doi: 10.1016/0304-3940(91)90045-u

Gong, C., Ennis, S. R., Hoff, J. T., and Keep, R. F. (2001). Inducible cyclooxygenase2 expression after experimental intracerebral hemorrhage. Brain Res. 901, 38-46. doi: 10.1016/s0006-8993(01)02186-2

Gout, P. W., Buckley, A. R., Simms, C. R., and Bruchovsky, N. (2001). Sulfasalazine, a potent suppressor of lymphoma growth by inhibition of the $\mathrm{x}(\mathrm{c})(-)$ cystine transporter: a new action for an old drug. Leukemia 15, 1633-1640. doi: $10.1038 /$ sj.leu. 2402238

Grossman, R. G., Frankowski, R. F., Burau, K. D., Toups, E. G., Crommett, J. W., Johnson, M. M., et al. (2012). Incidence and severity of acute complications after spinal cord injury. J. Neurosurg. Spine 17, 119-128.

Guan, X., Li, X., Yang, X., Yan, J., Shi, P., Ba, L., et al. (2019). The neuroprotective effects of carvacrol on ischemia/reperfusion-induced hippocampal neuronal impairment by ferroptosis mitigation. Life Sci. 235:116795. doi: 10.1016/j.lfs. 2019.116795

Guo, J., Li, Y., Chen, Z., He, Z., Zhang, B., Li, Y., et al. (2015). N-acetylcysteine treatment following spinal cord trauma reduces neural tissue damage and improves locomotor function in mice. Mol. Med. Rep. 12, 37-44. doi: 10.3892/ mmr.2015.3390

Guo, Y., Liu, X., Liu, D., Li, K., Wang, C., Liu, Y., et al. (2019). Inhibition of BECN1 suppresses lipid peroxidation by increasing system $\mathrm{Xc}(-)$ activity in early brain injury after subarachnoid hemorrhage. J. Mol. Neurosci. 67, 622-631. doi: $10.1007 / s 12031-019-01272-5$

Hadian, K., and Stockwell, B. R. (2020). SnapShot: ferroptosis. Cell 181, 11881188.e1. doi: 10.1016/j.cell.2020.04.039

Hall, E. D., Detloff, M. R., Johnson, K., and Kupina, N. C. (2004). Peroxynitrite-mediated protein nitration and lipid peroxidation in a mouse model of traumatic brain injury. J. Neurotrauma 21, 9-20. doi: 10.1089/ 089771504772695904

Hanson, L. R., Roeytenberg, A., Martinez, P. M., Coppes, V. G., Sweet, D. C., Rao, R. J., et al. (2009). Intranasal deferoxamine provides increased brain exposure and significant protection in rat ischemic stroke. J. Pharmacol. Exp. Ther. 330, 679-686. doi: 10.1124/jpet.108.149807

Hao, J., Li, B., Duan, H.-Q., Zhao, C.-X., Zhang, Y., Sun, C., et al. (2017). Mechanisms underlying the promotion of functional recovery by deferoxamine after spinal cord injury in rats. Neural. Regen. Res. 12, 959-968.
Hatakeyama, T., Okauchi, M., Hua, Y., Keep, R. F., and Xi, G. (2013). Deferoxamine reduces neuronal death and hematoma lysis after intracerebral hemorrhage in aged rats. Transl. Stroke Res. 4, 546-553. doi: 10.1007/s12975-013-0270-5

Hayano, M., Yang, W. S., Corn, C. K., Pagano, N. C., and Stockwell, B. R. (2016). Loss of cysteinyl-tRNA synthetase (CARS) induces the transsulfuration pathway and inhibits ferroptosis induced by cystine deprivation. Cell Death Differ. 23, 270-278. doi: 10.1038/cdd.2015.93

He, Y. J., Liu, X. Y., Xing, L., Wan, X., Chang, X., and Jiang, H. L. (2020). Fenton reaction-independent ferroptosis therapy via glutathione and iron redox couple sequentially triggered lipid peroxide generator. Biomaterials 241:119911. doi: 10.1016/j.biomaterials.2020.119911

Hinman, A., Holst, C. R., Latham, J. C., Bruegger, J. J., Ulas, G., McCusker, K. P., et al. (2018). Vitamin $\mathrm{E}$ hydroquinone is an endogenous regulator of ferroptosis via redox control of 15-lipoxygenase. PLoS One 13:e0201369. doi: 10.1371/ journal.pone. 0201369

Hirschhorn, T., and Stockwell, B. R. (2019). The development of the concept of ferroptosis. Free Radic. Biol. Med. 133, 130-143. doi: 10.1016/j.freeradbiomed. 2018.09.043

Hoffer, M. E., Balaban, C., Slade, M. D., Tsao, J. W., and Hoffer, B. (2013). Amelioration of acute sequelae of blast induced mild traumatic brain injury by $\mathrm{N}$-acetyl cysteine: a double-blind, placebo controlled study. PLoS One 8:e54163. doi: 10.1371/journal.pone.0054163

Homma, T., Kobayashi, S., Sato, H., and Fujii, J. (2019). Edaravone, a free radical scavenger, protects against ferroptotic cell death in vitro. Exp. Cell Res. 384:111592. doi: 10.1016/j.yexcr.2019.111592

Hsieh, C. H., Lin, Y. J., Chen, W. L., Huang, Y. C., Chang, C. W., Cheng, F. C., et al. (2017). HIF-1alpha triggers long-lasting glutamate excitotoxicity via system $\mathrm{xc}(-)$ in cerebral ischaemia-reperfusion. J. Pathol. 241, 337-349. doi: 10.1002/ path. 4838

Hu, W., Wang, H., Liu, Z., Liu, Y., Wang, R., Luo, X., et al. (2017). Neuroprotective effects of lycopene in spinal cord injury in rats via antioxidative and antiapoptotic pathway. Neurosci. Lett. 642, 107-112. doi: 10.1016/j.neulet.2017. 02.004

Hu, X., Tao, C., Gan, Q., Zheng, J., Li, H., and You, C. (2016). Oxidative stress in intracerebral hemorrhage: sources, mechanisms, and therapeutic targets. Oxid. Med. Cell. Longev. 2016:215391.

Hu, Z. X., Zhang, H., Yi, B., Yang, S. K., Liu, J., Hu, J., et al. (2020). VDR activation attenuate cisplatin induced AKI by inhibiting ferroptosis. Cell Death Dis. 11:73.

Huang, L. L., Liao, X. H., Sun, H., Jiang, X., Liu, Q., and Zhang, L. (2019). Augmenter of liver regeneration protects the kidney from ischaemiareperfusion injury in ferroptosis. J. Cell. Mol. Med. 23, 4153-4164. doi: 10.1111/ jcmm. 14302

Ingold, I., Berndt, C., Schmitt, S., Doll, S., Poschmann, G., Buday, K., et al. (2018). Selenium utilization by GPX4 is required to prevent hydroperoxide-induced ferroptosis. Cell 172, 409-422.e21. doi: 10.1016/j.cell.2017.11.048

Ishii, T., Bannai, S., and Sugita, Y. (1981). Mechanism of growth stimulation of L1210 cells by 2-mercaptoethanol in vitro. Role of the mixed disulfide of 2-mercaptoethanol and cysteine. J. Biol. Chem. 256, 12387-12392.

Jackman, N. A., Melchior, S. E., Hewett, J. A., and Hewett, S. J. (2012). Non-cell autonomous influence of the astrocyte system xc- on hypoglycaemic neuronal cell death. ASN Neuro 4:e00074.

Jiang, J. Y., Gao, G. Y., Feng, J. F., Mao, Q., Chen, L. G., Yang, X. F., et al. (2019). Traumatic brain injury in China. Lancet Neurol. 18, 286-295.

Kagan, V. E., Mao, G., Qu, F., Angeli, J. P., Doll, S., Croix, C. S., et al. (2017). Oxidized arachidonic and adrenic PEs navigate cells to ferroptosis. Nat. Chem. Biol. 13, 81-90. doi: 10.1038/nchembio.2238

Karalija, A., Novikova, L. N., Kingham, P. J., Wiberg, M., and Novikov, L. N. (2012). Neuroprotective effects of $\mathrm{N}$-acetyl-cysteine and acetyl-L-carnitine after spinal cord injury in adult rats. PLoS One 7:e41086. doi: 10.1371/journal.pone 0041086

Karalija, A., Novikova, L. N., Kingham, P. J., Wiberg, M., and Novikov, L. N. (2014). The effects of $\mathrm{N}$-acetyl-cysteine and acetyl-L-carnitine on neural survival, neuroinflammation and regeneration following spinal cord injury. Neuroscience 269, 143-151. doi: 10.1016/j.neuroscience.2014.03.042

Karuppagounder, S. S., Alin, L., Chen, Y., Brand, D., Bourassa, M. W., Dietrich, K., et al. (2018). N-acetylcysteine targets 5 lipoxygenase-derived, toxic lipids and can synergize with prostaglandin E2 to inhibit ferroptosis and improve 
outcomes following hemorrhagic stroke in mice. Ann. Neurol. 84, 854-872. doi: 10.1002/ana.25356

Kawai, H., Nakai, H., Suga, M., Yuki, S., Watanabe, T., and Saito, K. I. (1997). Effects of a novel free radical scavenger, $\mathrm{MCl}-186$, on ischemic brain damage in the rat distal middle cerebral artery occlusion model. J. Pharmacol. Exp. Ther. 281, 921-927.

Keep, R. F., Hua, Y., and Xi, G. (2012). Intracerebral haemorrhage: mechanisms of injury and therapeutic targets. Lancet Neurol. 11, 720-731. doi: 10.1016/s14744422(12)70104-7

Kenny, E. M., Fidan, E., Yang, Q., Anthonymuthu, T. S., New, L. A., Meyer, E. A., et al. (2019). Ferroptosis contributes to neuronal death and functional outcome after traumatic brain injury. Crit. Care Med. 47, 410-418. doi: 10.1097/ccm. 0000000000003555

Khalaf, S., Ahmad, A. S., Chamara, K. V. D. R., and Doré, S. (2018). Unique properties associated with the brain penetrant iron chelator HBED reveal remarkable beneficial effects after brain trauma. J. Neurotrauma 36, 43-53. doi: 10.1089/neu.2017.5617

Khoshnam, S. E., Winlow, W., Farzaneh, M., Farbood, Y., and Moghaddam, H. F. (2017). Pathogenic mechanisms following ischemic stroke. Neurol. Sci. 38, 1167-1186. doi: 10.1007/s10072-017-2938-1

Kondo, Y., Ogawa, N., Asanuma, M., Ota, Z., and Mori, A. (1995). Regional differences in late-onset iron deposition, ferritin, transferrin, astrocyte proliferation, and microglial activation after transient forebrain ischemia in rat brain. J. Cereb. Blood Flow Metab. 15, 216-226. doi: 10.1038/jcbfm.1995.27

Lan, B., Ge, J. W., Cheng, S. W., Zheng, X. L., Liao, J., He, C., et al. (2020). Extract of Naotaifang, a compound Chinese herbal medicine, protects neuron ferroptosis induced by acute cerebral ischemia in rats. J. Integr. Med. [Epub ahead of print].

Lapchak, P. A., and Zivin, J. A. (2009). The lipophilic multifunctional antioxidant edaravone (radicut) improves behavior following embolic strokes in rabbits: a combination therapy study with tissue plasminogen activator. Exp. Neurol. 215, 95-100. doi: 10.1016/j.expneurol.2008.09.004

Lei, P., Bai, T., and Sun, Y. (2019). Mechanisms of Ferroptosis and relations with regulated cell death: a review. Front. Physiol. 10:139. doi: 10.3389/fphys.2019. 00139

Leslie, S. W., Brown, L. M., Trent, R. D., Lee, Y. H., Morris, J. L., Jones, T. W., et al. (1992). Stimulation of N-Methyl-D-aspartate receptor-mediated calcium entry into dissociated neurons by reduced and oxidized glutathione. Mol. Pharmacol. $41,308-314$.

Lewerenz, J., Ates, G., Methner, A., Conrad, M., and Maher, P. (2018). Oxytosis/Ferroptosis-(Re-) Emerging roles for oxidative stress-dependent nonapoptotic cell death in diseases of the central nervous system. Front. Neurosci. 12:214. doi: 10.3389/fnins.2018.00214

Li, J., Cao, F., Yin, H. L., Huang, Z. J., Lin, Z. T., Mao, N., et al. (2020). Ferroptosis: past, present and future. Cell Death Dis. 11:88.

Li, Q., Han, X., Lan, X., Gao, Y., Wan, J., Durham, F., et al. (2017). Inhibition of neuronal ferroptosis protects hemorrhagic brain. JCI Insight 2:e90777.

Li, Q., Weiland, A., Chen, X., Lan, X., Han, X., Durham, F., et al. (2018). Ultrastructural characteristics of neuronal death and white matter injury in mouse brain tissues after intracerebral hemorrhage: coexistence of ferroptosis, autophagy, and necrosis. Front. Neurol. 9:581. doi: 10.3389/fneur.2018.00581

Li, S., Jiang, D., Rosenkrans, Z. T., Barnhart, T. E., Ehlerding, E. B., Ni, D., et al. (2019a). Aptamer-conjugated framework nucleic acids for the repair of cerebral ischemia-reperfusion injury. Nano Lett. 19, 7334-7341. doi: 10.1021/ acs.nanolett.9b02958

Li, X., Zhan, J., Hou, Y., Chen, S., Hou, Y., Xiao, Z., et al. (2019b). Coenzyme Q10 suppresses oxidative stress and apoptosis via activating the Nrf-2/NQO-1 and NF-кB signaling pathway after spinal cord injury in rats. Am. J. Transl. Res. 11, 6544-6552.

Li, X., Zhan, J., Hou, Y., Hou, Y., Chen, S., Luo, D., et al. (2019c). Coenzyme Q10 regulation of apoptosis and oxidative stress in $\mathrm{H} 2 \mathrm{O} 2$ induced BMSC death by modulating the Nrf-2/NQO-1 signaling pathway and its application in a model of spinal cord injury. Oxid. Med. Cell. Longev. 2019:6493081.

Li, X., Zhuang, X., and Qiao, T. (2019d). Role of ferroptosis in the process of acute radiation-induced lung injury in mice. Biochem. Biophys. Res. Commun. 519, 240-245. doi: 10.1016/j.bbrc.2019.08.165

Li, Y. C., Cao, Y. M., Xiao, J., Shang, J. W., Tan, Q., Ping, F., et al. (2020). Inhibitor of apoptosis-stimulating protein of p53 inhibits ferroptosis and alleviates intestinal ischemia/reperfusion-induced acute lung injury. Cell Death Differ.
Liang, W., Huang, X., and Chen, W. (2017). The effects of baicalin and baicalein on cerebral ischemia: a review. Aging Dis. 8, 850-867.

Lipscomb, D. C., Gorman, L. G., Traystman, R. J., and Hurn, P. D. (1998). Low molecular weight iron in cerebral ischemic acidosis in vivo. Stroke 29, 487-492.

Liu, J., Tang, T., and Yang, H. (2011). Protective effect of deferoxamine on experimental spinal cord injury in rat. Injury 42, 742-745. doi: 10.1016/j.injury. 2010.08.028

Liu, J.-B., Tang, T.-S., and Xiao, D.-S. (2004). Changes of free iron contents and its correlation with lipid peroxidation after experimental spinal cord injury. Chin J. Traumatol. 7, 229-232.

Liu, Y., Wang, W., Li, Y., Xiao, Y., Cheng, J., and Jia, J. (2015). The 5-Lipoxygenase inhibitor zileuton confers neuroprotection against glutamate oxidative damage by inhibiting ferroptosis. Biol. Pharm. Bull. 38, 1234-1239. doi: 10.1248/bpb. b15-00048

Lorente, L., Martín, M. M., Abreu-González, P., Ramos, L., Argueso, M., Cáceres, J. J., et al. (2015). Association between serum malondialdehyde levels and mortality in patients with severe brain trauma injury. J. Neurotrauma 32, 1-6. doi: $10.1089 /$ neu. 2014.3456

Lorincz, T., Jemnitz, K., Kardon, T., Mandl, J., and Szarka, A. (2015). Ferroptosis is involved in acetaminophen induced cell death. Pathol. Oncol. Res. 21, 11151121. doi: 10.1007/s12253-015-9946-3

Lozano, D., Gonzales-Portillo, G. S., Acosta, S., de la Pena, I., Tajiri, N., Kaneko, Y., et al. (2015). Neuroinflammatory responses to traumatic brain injury: etiology, clinical consequences, and therapeutic opportunities. Neuropsychiatr. Dis. Treat. 11, 97-106.

Lu, L., Cao, H., Wei, X., Li, Y., and Li, W. (2015). Iron deposition is positively related to cognitive impairment in patients with chronic mild traumatic brain injury: assessment with susceptibility weighted imaging. BioMed Res. Int. 2015:470676

Lv, H., Zhen, C., Liu, J., Yang, P., Hu, L., and Shang, P. (2019). Unraveling the potential role of glutathione in multiple forms of cell death in cancer therapy. Oxid. Med. Cell. Longev. 2019:3150145.

Maas, A. I. R., Menon, D. K., Adelson, P. D., Andelic, N., Bell, M. J., Belli, A., et al. (2017). In, and investigators, traumatic brain injury: integrated approaches to improve prevention, clinical care, and research. Lancet Neurol. 16, 987-1048.

Morris, G., Anderson, G., Berk, M., and Maes, M. (2013). Coenzyme Q10 depletion in medical and neuropsychiatric disorders: potential repercussions and therapeutic implications. Mol. Neurobiol. 48, 883-903. doi: 10.1007/ s12035-013-8477-8

Morris, G., Berk, M., Carvalho, A. F., Maes, M., Walker, A. J., and Puri, B. K. (2018). Why should neuroscientists worry about iron? The emerging role of ferroptosis in the pathophysiology of neuroprogressive diseases. Behav. Brain Res. 341, 154-175. doi: 10.1016/j.bbr.2017.12.036

Nakamura, T., Keep, R. F., Hua, Y., Schallert, T., Hoff, J. T., and Xi, G. (2004). Deferoxamine-induced attenuation of brain edema and neurological deficits in a rat model of intracerebral hemorrhage. J. Neurosurg. 100, 672-678. doi: 10.3171/jns.2004.100.4.0672

Nasoohi, S., Simani, L., Khodagholi, F., Nikseresht, S., Faizi, M., and Naderi, N. (2019). Coenzyme Q10 supplementation improves acute outcomes of stroke in rats pretreated with atorvastatin. Nutr. Neurosci. 22, 264-272. doi: 10.1080/ 1028415x.2017.1376928

Nazemi, Z., Nourbakhsh, M. S., Kiani, S., Heydari, Y., Ashtiani, M. K., Daemi, H., et al. (2020). Co-delivery of minocycline and paclitaxel from injectable hydrogel for treatment of spinal cord injury. J. Control Release 321, 145-158. doi: 10.1016/j.jconrel.2020.02.009

Nishi, H., Watanabe, T., Sakurai, H., Yuki, S., and Ishibashi, A. (1989). Effect of MCI-186 on brain edema in rats. Stroke 20, 1236-1240. doi: 10.1161/01.str.20. 9.1236

Nour, M., Scalzo, F., and Liebeskind, D. S. (2013). Ischemia-reperfusion injury in stroke. Interv. Neurol. 1, 185-199.

Ottestad-Hansen, S., Hu, Q. X., Follin-Arbelet, V. V., Bentea, E., Sato, H., Massie, A., et al. (2018). The cystine-glutamate exchanger (xCT, Slc7a11) is expressed in significant concentrations in a subpopulation of astrocytes in the mouse brain. Glia 66, 951-970. doi: 10.1002/glia.23294

Park, T. J., Park, J. H., Lee, G. S., Lee, J. Y., Shin, J. H., Kim, M. W., et al. (2019). Quantitative proteomic analyses reveal that GPX4 downregulation during myocardial infarction contributes to ferroptosis in cardiomyocytes. Cell Death Dis. 10:835 
Park, U. J., Lee, Y. A., Won, S. M., Lee, J. H., Kang, S.-H., Springer, J. E., et al. (2011). Blood-derived iron mediates free radical production and neuronal death in the hippocampal CA1 area following transient forebrain ischemia in rat. Acta Neuropathol. 121, 459-473. doi: 10.1007/s00401-010-0785-8

Patel, S. P., Sullivan, P. G., Pandya, J. D., Goldstein, G. A., VanRooyen, J. L., Yonutas, H. M., et al. (2014). N-acetylcysteine amide preserves mitochondrial bioenergetics and improves functional recovery following spinal trauma. Exp. Neurol. 257, 95-105. doi: 10.1016/j.expneurol.2014.04.026

Paterniti, I., Mazzon, E., Emanuela, E., Paola, R. D., Galuppo, M., Bramanti, P., et al. (2010). Modulation of inflammatory response after spinal cord trauma with deferoxamine, an iron chelator. Free Radic. Res. 44, 694-709. doi: 10.3109/ 10715761003742993

Pearn, M. L. I, Niesman, R., Egawa, J., Sawada, A., Almenar-Queralt, A., Shah, S. B., et al. (2017). Pathophysiology associated with traumatic brain injury: current treatments and potential novel therapeutics. Cell. Mol. Neurobiol. 37, 571-585. doi: 10.1007/s10571-016-0400-1

Portbury, S. D., Hare, D. J., Sgambelloni, C., Finkelstein, D. I., and Adlard, P. A. (2016). A time-course analysis of changes in cerebral metal levels following a controlled cortical impact. Metallomics 8, 193-200. doi: 10.1039/c5mt00234f

Portbury, S. D., Hare, D. J., Sgambelloni, C. J., Bishop, D. P., Finkelstein, D. I., Doble, P. A., et al. (2017). Age modulates the injury-induced metallomic profile in the brain. Metallomics 9, 402-410. doi: 10.1039/c6mt00260a

Qureshi, A. I., Ling, G. S., Khan, J., Suri, M. F., Miskolczi, L., Guterman, L. R., et al. (2001). Quantitative analysis of injured, necrotic, and apoptotic cells in a new experimental model of intracerebral hemorrhage. Crit. Care Med. 29, 152-157. doi: 10.1097/00003246-200101000-00030

Qureshi, A. I., Suri, M. F. K., Ostrow, P. T., Kim, S. H., Ali, Z., Shatla, A. A., et al. (2003). Apoptosis as a form of cell death in intracerebral hemorrhage. Neurosurgery 52, 1041-1047.

Rai, G., Joshi, N., Jung, J. E., Liu, Y., Schultz, L., Yasgar, A., et al. (2014). Potent and selective inhibitors of human reticulocyte 12/15-lipoxygenase as anti-stroke therapies. J. Med. Chem. 57, 4035-4048. doi: 10.1021/jm401915r

Ramezani, M., Sahraei, Z., Simani, L., Heydari, K., and Shahidi, F. (2018). Coenzyme Q10 supplementation in acute ischemic stroke: is it beneficial in short-term administration? Nutr. Neurosci. 1-6. doi: 10.1080/1028415x.2018. 1541269 [Epub ahead of print].

Readnower, R. D., Chavko, M., Adeeb, S., Conroy, M. D., Pauly, J. R., McCarron, R. M., et al. (2010). Increase in blood-brain barrier permeability, oxidative stress, and activated microglia in a rat model of blast-induced traumatic brain injury. J. Neurosci. Res. 88, 3530-3539. doi: 10.1002/jnr.22510

Roth, T. L., Nayak, D., Atanasijevic, T., Koretsky, A. P., Latour, L. L., and McGavern, D. B. (2014). Transcranial amelioration of inflammation and cell death after brain injury. Nature 505, 223-228. doi: 10.1038/nature12808

Sandercock, P., Wardlaw, J. M., Lindley, R. I., Dennis, M., Cohen, G., Murray, G., et al. (2012). The benefits and harms of intravenous thrombolysis with recombinant tissue plasminogen activator within $6 \mathrm{~h}$ of acute ischaemic stroke (the third international stroke trial [IST-3]): a randomised controlled trial. Lancet 379, 2352-2363. doi: 10.1016/s0140-6736(12)60768-5

Sauerbeck, A., Schonberg, D. L., Laws, J. L., and McTigue, D. M. (2013). Systemic iron chelation results in limited functional and histological recovery after traumatic spinal cord injury in rats. Exp. Neurol. 248, 53-61. doi: 10.1016/j. expneurol.2013.05.011

Savelev, S. U., Okello, E. J., and Perry, E. K. (2004). Butyryl- and acetylcholinesterase inhibitory activities in essential oils of Salvia species and their constituents. Phytother. Res. 18, 315-324. doi: 10.1002/ptr.1451

Seiler, A., Schneider, M., Förster, H., Roth, S., Wirth, E. K., Culmsee, C., et al. (2008). Glutathione peroxidase 4 senses and translates oxidative stress into 12/15-lipoxygenase dependent- and AIF-mediated cell death. Cell Metab. 8, 237-248. doi: 10.1016/j.cmet.2008.07.005

Selim, M. H., and Ratan, R. R. (2004). The role of iron neurotoxicity in ischemic stroke. Ageing Res. Rev. 3, 345-353. doi: 10.1016/j.arr.2004.04.001

Senol, N., Nazı roglu, M., and Yürüker, V. (2014). N-acetylcysteine and selenium modulate oxidative stress, antioxidant vitamin and cytokine values in traumatic brain injury-induced rats. Neurochem. Res. 39, 685-692. doi: 10.1007/s11064014-1255-9

Shang, Y., Luo, M., Yao, F., Wang, S., Yuan, Z., and Yang, Y. (2020). Ceruloplasmin suppresses ferroptosis by regulating iron homeostasis in hepatocellular carcinoma cells. Cell Signal. 72:109633. doi: 10.1016/j.cellsig.2020.109633
Shen, L. D., Qi, W. H., Bai, J. J., Zuo, C. Y., Bai, D. L., Gao, W. D., et al. (2020). Resibufogenin inhibited colorectal cancer cell growth and tumorigenesis through triggering ferroptosis and ROS production mediated by GPX4 inactivation. Anat. Rec. [Epub ahead of print].

Shimada, K., Skouta, R., Kaplan, A., Yang, W. S., Hayano, M., Dixon, S. J., et al. (2016). Global survey of cell death mechanisms reveals metabolic regulation of ferroptosis. Nat. Chem. Biol. 12, 497-503. doi: 10.1038/nchembio.2079

Siddiq, A., Aminova, L. R., Troy, C. M., Suh, K., Messer, Z., Semenza, G. L., et al. (2009). Selective inhibition of hypoxia-inducible factor (HIF) prolylhydroxylase 1 mediates neuroprotection against normoxic oxidative death via HIF- and CREB-independent pathways. J. Neurosci. 29, 8828-8838. doi: 10. 1523/jneurosci.1779-09.2009

Silva, N. A., Sousa, N., Reis, R. L., and Salgado, A. J. (2014). From basics to clinical: a comprehensive review on spinal cord injury. Prog. Neurobiol. 114, 25-57. doi: 10.1016/j.pneurobio.2013.11.002

Soria, F. N., Perez-Samartin, A., Martin, A., Gona, K. B., Llop, J., Szczupak, B., et al. (2014). Extrasynaptic glutamate release through cystine/glutamate antiporter contributes to ischemic damage. J. Clin. Invest. 124, 3645-3655. doi: 10.1172/ jci71886

Speer, R. E., Karuppagounder, S. S., Basso, M., Sleiman, S. F., Kumar, A., Brand, D., et al. (2013). Hypoxia-inducible factor prolyl hydroxylases as targets for neuroprotection by "antioxidant" metal chelators: from ferroptosis to stroke. Free Radic. Biol. Med. 62, 26-36. doi: 10.1016/j.freeradbiomed.2013. 01.026

Stockwell, B. R., Friedmann Angeli, J. P., Bayir, H., Bush, A. I., Conrad, M., Dixon, S. J., et al. (2017). Ferroptosis: a regulated cell death nexus linking metabolism, redox biology, and disease. Cell 171, 273-285. doi: 10.1016/j.cell.2017.09.021

Su, Y., Zhao, B., Zhou, L., Zhang, Z., Shen, Y., Lv, H., et al. (2020). Ferroptosis, a novel pharmacological mechanism of anti-cancer drugs. Cancer Lett. 483, 127-136. doi: 10.1016/j.canlet.2020.02.015

Sun, Y., Zheng, Y., Wang, C., and Liu, Y. (2018). Glutathione depletion induces ferroptosis, autophagy, and premature cell senescence in retinal pigment epithelial cells. Cell Death Dis. 9:753.

Thorn, T. L., He, Y., Jackman, N. A., Lobner, D., Hewett, J. A., and Hewett, S. J. (2015). A cytotoxic co-operative interaction between energy deprivation and glutamate release from system $\mathrm{x}(\mathrm{c})(-)$ mediates aglycemic neuronal cell death. ASN Neuro 7:759091415614301.

Tomimoto, H., Shibata, M., Ihara, M., Akiguchi, I., Ohtani, R., and Budka, H. (2002). A comparative study on the expression of cyclooxygenase and 5lipoxygenase during cerebral ischemia in humans. Acta Neuropathol. 104, 601-607. doi: 10.1007/s00401-002-0590-0

Tran, A. P., Warren, P. M., and Silver, J. (2018). The biology of regeneration failure and success after spinal cord injury. Physiol. Rev. 98, 881-917. doi: 10.1152/physrev.00017.2017

Tsai, T. H., Liu, S. C., Tsai, P. L., Ho, L. K., Shum, A. Y. C., and Chen, C. F. (2002). The effects of the cyclosporin A, a P-glycoprotein inhibitor, on the pharmacokinetics of baicalein in the rat: a microdialysis study. Br. J. Pharmacol. 137, 1314-1320. doi: 10.1038/sj.bjp.0704959

Tuo, Q. Z., Lei, P., Jackman, K. A., Li, X. L., Xiong, H., Li, X. L., et al. (2017). Taumediated iron export prevents ferroptotic damage after ischemic stroke. Mol. Psychiatry 22, 1520-1530. doi: 10.1038/mp.2017.171

Varga, V., Jenei, Z., Janaky, R., Saransaari, P., and Oja, S. S. (1997). Glutathione is an endogenous ligand of rat brain N-methyl-D-aspartate (n.d.) and 2-amino-3hydroxy-5-methyl-4-isoxazolepropionate (AMPA) receptors. Neurochem. Res. 22, 1165-1171.

Visavadiya, N. P., Patel, S. P., VanRooyen, J. L., Sullivan, P. G., and Rabchevsky, A. G. (2016). Cellular and subcellular oxidative stress parameters following severe spinal cord injury. Redox Biol. 8, 59-67. doi: 10.1016/j.redox.2015. 12.011

Viswanathan, V. S., Ryan, M. J., Dhruv, H. D., Gill, S., Eichhoff, O. M., SeashoreLudlow, B., et al. (2017). Dependency of a therapy-resistant state of cancer cells on a lipid peroxidase pathway. Nature 547, 453-457.

Wang, K.-Y., Wu, C.-H., Zhou, L.-Y., Yan, X.-H., Yang, R.-L., Liao, L.-M., et al. (2015). Ultrastructural changes of brain tissues surrounding hematomas after intracerebral hemorrhage. Eur. Neurol. 74, 28-35. doi: 10.1159/000434631

Ward, R. J., Zucca, F. A., Duyn, J. H., Crichton, R. R., and Zecca, L. (2014). The role of iron in brain ageing and neurodegenerative disorders. Lancet Neurol. 13, 1045-1060. doi: 10.1016/s1474-4422(14)70117-6 
Watanabe, K., Tanaka, M., Yuki, S., Hirai, M., and Yamamoto, Y. (2018). How is edaravone effective against acute ischemic stroke and amyotrophic lateral sclerosis? J. Clin. Biochem. Nutr. 62, 20-38. doi: 10.3164/jcbn.17-62

Wenzel, S. E., Tyurina, Y. Y., Zhao, J., St Croix, C. M., Dar, H. H., Mao, G., et al. (2017). PEBP1 wardens ferroptosis by enabling lipoxygenase generation of lipid death signals. Cell 171, 628-641.e26. doi: 10.1016/j.cell.2017.09.044

Winterbourn, C. C. (1995). Toxicity of iron and hydrogen peroxide: the Fenton reaction. Toxicol. Lett. 8, 969-974. doi: 10.1016/0378-4274(95)03532-x

Witschi, A., Reddy, S., Stofer, B., and Lauterburg, B. H. (1992). The systemic availability of oral glutathione. Eur. J. Clin. Pharmacol. 43, 667-669. doi: 10. 1007/bf02284971

Wolpaw, A. J., Shimada, K., Skouta, R., Welsch, M. E., Akavia, U. D., Pe’er, D., et al. (2011). Modulatory profiling identifies mechanisms of small molecule-induced cell death. Proc. Natl. Acad. Sci. U.S.A. 108, E771-E780.

Wu, C., Zhao, W., Yu, J., Li, S., Lin, L., and Chen, X. (2018). Induction of ferroptosis and mitochondrial dysfunction by oxidative stress in PC12 cells. Sci. Rep. 8:574.

Wu, H., Wu, T., Li, M., and Wang, J. (2012). Efficacy of the lipid-soluble iron chelator 2,2'-dipyridyl against hemorrhagic brain injury. Neurobiol. Dis. 45, 388-394. doi: 10.1016/j.nbd.2011.08.028

Wu, H., Wu, T., Xu, X., Wang, J., and Wang, J. (2011). Iron toxicity in mice with collagenase-induced intracerebral hemorrhage. J. Cereb. Blood Flow Metab. 31, 1243-1250. doi: 10.1038/jcbfm.2010.209

Wu, J., Hua, Y., Keep, R. F., Nakamura, T., Hoff, J. T., and Xi, G. (2003). Iron and iron-handling proteins in the brain after intracerebral hemorrhage. Stroke 34, 2964-2969. doi: 10.1161/01.str.0000103140.52838.45

Wu, J., Yang, J. J., Cao, Y., Li, H., Zhao, H., Yang, S., et al. (2020). Iron overload contributes to general anaesthesia-induced neurotoxicity and cognitive deficits. J. Neuroinflamm. 17:110.

Xiao, X., Jiang, Y., Liang, W., Wang, Y., Cao, S., Yan, H., et al. (2019). miR-212-5p attenuates ferroptotic neuronal death after traumatic brain injury by targeting Ptgs2. Mol. Brain 12:78.

Xie, B. S., Wang, Y. Q., Lin, Y., Mao, Q., Feng, J. F., Gao, G. Y., et al. (2019). Inhibition of ferroptosis attenuates tissue damage and improves long-term outcomes after traumatic brain injury in mice. CNS Neurosci. Ther. 25, 465-475. doi: $10.1111 / \mathrm{cns} .13069$

Xie, Y., Hou, W., Song, X., Yu, Y., Huang, J., Sun, X., et al. (2016). Ferroptosis: process and function. Cell Death Differ. 23, 369-379. doi: 10.1038/cdd.2015.158

Yagoda, N., von Rechenberg, M., Zaganjor, E., Bauer, A. J., Yang, W. S., Fridman, D. J., et al. (2007). RAS-RAF-MEK-dependent oxidative cell death involving voltage-dependent anion channels. Nature 447, 864-868.

Yamada, N., Karasawa, T., Kimura, H., Watanabe, S., Komada, T., Kamata, R., et al. (2020). Ferroptosis driven by radical oxidation of n-6 polyunsaturated fatty acids mediates acetaminophen-induced acute liver failure. Cell Death Dis. $11: 144$.

Yang, W. S., Kim, K. J., Gaschler, M. M., Patel, M., Shchepinov, M. S., and Stockwell, B. R. (2016). Peroxidation of polyunsaturated fatty acids by lipoxygenases drives ferroptosis. Proc. Natl. Acad. Sci. U.S.A. 113, E4966-E4975.

Yang, W. S., SriRamaratnam, R., Welsch, M. E., Shimada, K., Skouta, R., Viswanathan, V. S., et al. (2014). Regulation of ferroptotic cancer cell death by GPX4. Cell 156, 317-331. doi: 10.1016/j.cell.2013.12.010

Yang, W. S., and Stockwell, B. R. (2008). Synthetic lethal screening identifies compounds activating iron-dependent, nonapoptotic cell death in oncogenicRAS-harboring cancer cells. Chem. Biol. 15, 234-245. doi: 10.1016/j.chembiol. 2008.02.010

Ye, L. F., Chaudhary, K. R., Zandkarimi, F., Harken, A. D., Kinslow, C. J., Upadhyayula, P. S., et al. (2020). Radiation-induced lipid peroxidation triggers ferroptosis and synergizes with ferroptosis inducers. ACS Chem. Biol. 15, 469-484. doi: 10.1021/acschembio.9b00939

Yigitkanli, K., Pekcec, A., Karatas, H., Pallast, S., Mandeville, E., Joshi, N., et al. (2013). Inhibition of 12/15-lipoxygenase as therapeutic strategy to treat stroke. Ann. Neurol. 73, 129-135. doi: 10.1002/ana.23734

Yu, H., Zhang, Z. L., Chen, J., Pei, A., Hua, F., Qian, X., et al. (2012). Carvacrol, a food-additive, provides neuroprotection on focal cerebral ischemia/reperfusion injury in mice. PLoS One 7:e33584. doi: 10.1371/journal.pone.0033584

Yuan, H., Li, X., Zhang, X., Kang, R., and Tang, D. (2016). Identification of ACSL4 as a biomarker and contributor of ferroptosis. Biochem. Biophys. Res. Commun. 478, 1338-1343. doi: 10.1016/j.bbrc.2016.08.124

Zeng, L., Tan, L., Li, H., Zhang, Q., Li, Y., and Guo, J. (2018). Deferoxamine therapy for intracerebral hemorrhage: a systematic review. PLoS One 13:e0193615. doi: 10.1371/journal.pone.0193615

Zhang, K., Tu, M., Gao, W., Cai, X., Song, F., Chen, Z., et al. (2019). Hollow prussian blue nanozymes drive neuroprotection against ischemic stroke via attenuating oxidative stress, counteracting inflammation, and suppressing cell apoptosis. Nano Lett. 19, 2812-2823. doi: 10.1021/acs.nanolett.8b04729

Zhang, L., Hu, R., Li, M., Li, F., Meng, H., Zhu, G., et al. (2013). Deferoxamine attenuates iron-induced long-term neurotoxicity in rats with traumatic brain injury. Neurol. Sci. 34, 639-645. doi: 10.1007/s10072-012-1090-1

Zhang, Y., Sun, C., Zhao, C., Hao, J., Zhang, Y., Fan, B., et al. (2019). Ferroptosis inhibitor SRS 16-86 attenuates ferroptosis and promotes functional recovery in contusion spinal cord injury. Brain Res. 1706, 48-57. doi: 10.1016/j.brainres. 2018.10.023

Zhang, Z., Wu, Y., Yuan, S., Zhang, P., Zhang, J., Li, H., et al. (2018). Glutathione peroxidase 4 participates in secondary brain injury through mediating ferroptosis in a rat model of intracerebral hemorrhage. Brain Res. 1701, 112-125. doi: 10.1016/j.brainres.2018.09.012

Zhao, X., Zhang, Y., Strong, R., Zhang, J., Grotta, J. C., and Aronowski, J. (2007). Distinct patterns of intracerebral hemorrhage-induced alterations in NF-kappaB subunit, iNOS, and COX-2 expression. J. Neurochem. 101, 652-663. doi: $10.1111 / \mathrm{j} .1471-4159.2006 .04414 . \mathrm{x}$

Zhong, H., and Yin, H. (2015). Role of lipid peroxidation derived 4hydroxynonenal (4-HNE) in cancer: focusing on mitochondria. Redox Biol. 4, 193-199. doi: 10.1016/j.redox.2014.12.011

Zhou, Y., Wang, H.-D., Zhou, X.-M., Fang, J., Zhu, L., and Ding, K. (2018). $\mathrm{N}$-acetylcysteine amide provides neuroprotection via Nrf2-ARE pathway in a mouse model of traumatic brain injury. Drug Des. Dev. Ther. 12, 4117-4127. doi: $10.2147 /$ dddt.s179227

Zille, M., Karuppagounder, S. S., Chen, Y., Gough, P. J., Bertin, J., Finger, J., et al. (2017). Neuronal death after hemorrhagic stroke in vitro and in vivo shares features of ferroptosis and necroptosis. Stroke 48, 1033-1043. doi: 10.1161/ strokeaha.116.015609

Conflict of Interest: The authors declare that the research was conducted in the absence of any commercial or financial relationships that could be construed as a potential conflict of interest.

Copyright $\odot 2020$ Shen, Lin, Li, Wu, Lenahan, Pan, Xu, Chen, Shao and Zhang. This is an open-access article distributed under the terms of the Creative Commons Attribution License (CC BY). The use, distribution or reproduction in other forums is permitted, provided the original author(s) and the copyright owner(s) are credited and that the original publication in this journal is cited, in accordance with accepted academic practice. No use, distribution or reproduction is permitted which does not comply with these terms. 